\title{
The Dictyostelium discoideum RACK1 orthologue has roles in growth and development
}

\author{
Napoleon Nosa Omosigho', Karthic Swaminathan', Markus Plomann², Annette Müller-Taubenberger, \\ Angelika A Noegel ${ }^{1 *}$ and Tanja Y Riyahi ${ }^{1 *}$
}

\begin{abstract}
Background: The receptor for activated C-kinase 1 (RACK1) is a conserved protein belonging to the WD40 repeat family of proteins. It folds into a beta propeller with seven blades which allow interactions with many proteins. Thus it can serve as a scaffolding protein and have roles in several cellular processes.

Results: We identified the product of the Dictyostelium discoideum gpbB gene as the Dictyostelium RACK1 homolog. The protein is mainly cytosolic but can also associate with cellular membranes. DdRACK1 binds to phosphoinositides (PIPs) in protein-lipid overlay and liposome-binding assays. The basis of this activity resides in a basic region located in the extended loop between blades 6 and 7 as revealed by mutational analysis. Similar to RACK1 proteins from other organisms DdRACK1 interacts with $\mathrm{G}$ protein subunits alpha, beta and gamma as shown by yeast two-hybrid, pulldown, and immunoprecipitation assays. Unlike the Saccharomyces cerevisiae and Cryptococcus neoformans RACK1 proteins it does not appear to take over $\mathrm{G} \beta$ function in $D$. discoideum as developmental and other defects were not rescued in G $\beta$ null mutants overexpressing GFP-DdRACK1. Overexpression of GFP-tagged DdRACK1 and a mutant version (DdRACK1 mut) which carried a charge-reversal mutation in the basic region in wild type cells led to changes during growth and development.
\end{abstract}

Conclusion: DdRACK1 interacts with heterotrimeric G proteins and can through these interactions impact on processes specifically regulated by these proteins.

Keywords: Dictyostelium discoideum, G protein signaling, RACK1, WD40 repeat protein, Phosphoinositides, Phosphorylation, Dimerization

\section{Background}

Every cell has the capability to detect extracellular signals, and then mounts an appropriate response to these signals. Specific stimuli include light, hormones, neurotransmitters, growth factors, and odorants. They are sensed by cell surface receptors which in case of $G$ protein-coupled receptors interact with heterotrimeric guanine nucleotide binding proteins (G proteins), key intermediates in cellular signaling processes that link the receptors with intracellular effector proteins generating cellular responses $[1,2]$.

\footnotetext{
*Correspondence: noegel@uni-koeln.de; triyahi@uni-koeln.de 'Institute of Biochemistry I, Medical Faculty, Center for Molecular Medicine Cologne (CMMC) and Cologne Excellence Cluster on Cellular Stress Responses in Aging-Associated Diseases (CECAD), University of Cologne, 50931 Köln, Germany

Full list of author information is available at the end of the article
}

The heterotrimeric G proteins consist of $\alpha, \beta$, and $\gamma$ subunits. Upon binding of agonist to the receptor, a conformational change in the $G \alpha$ subunit promotes the release of GDP and binding to GTP which then releases $G \beta \gamma$ [2]. The liberated G $\beta \gamma$ subunits play critical roles in many cellular processes $[3,4]$. They regulate a variety of effector molecules ranging from enzymes, such as phospholipase $C \beta$ (PLC $\beta$ ) and adenylyl cyclase, to ion channels. The G $\beta \gamma$ complex functions at many levels to promote and restrict signaling at the plasma membrane. It can act as a guanine nucleotide dissociation inhibitor (GDI) to prevent spontaneous exchange of GTP for

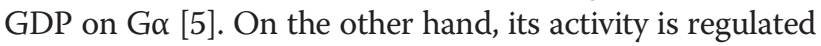
by a number of interacting proteins which can also represent effectors. Such proteins are phosducin, phosducinlike proteins, and $\mathrm{G}$ protein-coupled receptor kinases (GRKs) [6,7]. G $\beta$ subunits adopt a distinct seven-bladed propeller structure with each blade composed of a 
conserved core of $\sim 40$ amino acids flanked by Trp-Asp (WD) $[8,9]$. Unlike higher eukaryotes in which multiple G $\beta$ subunits have been identified [10], $D$. discoideum harbors a single $G \beta$, one $G \gamma$, and twelve G $\alpha$ subunits [11-13]. All the $G \alpha$ subunits are expected to interact with the same GBY dimer. D. discoideum development is relatively simple as compared to higher eukaryotes. The roles of its individual $\mathrm{G \alpha}$ subunits, however, appear to be quite distinct with respect to developmental morphology and cellular differentiation as indicated by the phenotypes of gene disruption or overexpression mutants. G $\alpha 2$ is required for adenylyl cyclase A (ACA), guanylyl cyclase (GC) and phospholipase C (PLC) activation. Ga2-null mutants do not aggregate and overexpression of wild-type $\mathrm{G} \alpha 2$ results in precocious activation of guanylyl cyclase by cAMP in vegetative cells [14]. Ga4 mediates responses to folic acid [15], and Go8 inhibits proliferation, promotes adhesion and regulates cell differentiation [16]. D. discoideum cells lacking functional $\mathrm{G}$ protein $\beta$ subunit are severely defective in phagocytosis, chemotaxis, aggregation, and development $[17,12,18-21]$.

RACK1 (Receptor for activated C kinase 1) is present in organisms from all eukaryotic kingdoms like plants, fungi and animals. S. cerevisiae cells lacking RACK1 are viable whereas in a mouse model RACK1 depletion causes lethality at gastrulation [22]. The protein was originally found in association with activated protein kinase $\mathrm{C}$ (PKC) where it acted as a scaffold protein serving as a platform for connecting PKC with its substrates, and was responsible for the association of activated PKC with cellular membranes $[23,24]$. The mechanism of membrane interaction is poorly understood. One prediction is that the anchoring protein should always be localized to the same site as its interaction partners. For instance, RACK1 accompanies PKC $\beta I I$ to its site of action in response to its activation [24]. RACK1 interacts with many receptors and their precursors and is involved in their localization. Furthermore RACK1 has been shown to interact with subunits of the heterotrimeric G proteins [25-28].

RACK1 structurally mimics a G $\beta$ harboring seven WD repeats which build up the seven-bladed beta-propeller. Different from G $\beta$ RACK1 lacks the typical N-terminal alpha helix which is necessary for the tight interaction of Gß with the Gy subunit. In S. cerevisiae and C. neoformans, which possess only one GßY subunit but multiple Go subunits, RACK1 has been reported to interact with free $\mathrm{G} \alpha$ and $\mathrm{G \gamma}$; interactions with the heterotrimeric $\mathrm{G} \beta \gamma$ subunits were shown as well $[29,30]$. Furthermore, RACK1 was found as a part of the ribosome complex and could thereby be involved in protein translation. Thus RACK1 is a versatile and dynamic component which is involved in many cellular processes far more than PKC could mediate [31,32].
Here we show that $D$. discoideum GpbB (DDB0185122) which is described as a G $\beta$-like protein in the databases is a RACK1 homolog. We initially identified GbpB as a binding partner of RpkA, an unusual $G$ protein coupled receptor (GPCR) which functions in phagocytosis and antibacterial defense in $D$. discoideum [33]. RpkA has a lipid kinase domain at its $\mathrm{C}$-terminus which contains the interaction site for RACK1. We characterized the protein with regard to its dimerization properties, studied its localization and expression during development and possible interactions with $\mathrm{G}$ proteins. Furthermore we uncovered a lipid binding property which is mediated by a unique extended basic loop between blades 6 and 7 of the propeller.

\section{Results}

\section{Characterization of $D$. discoideum RACK1 (DdRACK1)}

gpbB (DDB_G0275045) is located on chromosome 2 of the $D$. discoideum genome and has 2 exons. The open reading frame encompasses $1136 \mathrm{bp}$ which encodes a protein of 329 amino acids migrating as a $36 \mathrm{kDa}$ protein on SDS polyacrylamide gels. Blast results showed that GpbB is highly related to the RACK1 family of proteins and the alignment of RACK1 sequences from diverse organisms such as $H$. sapiens, D. melanogaster, A. thaliana, D. discoideum and S. cerevisiae revealed significant sequence identity. The greatest difference is observed between propeller blades 6 and 7 where an extended loop of mainly basic amino acids is present in the $D$. discoideum and the $A$. thaliana RACK1 proteins (Figure 1A).

$G \beta$ was the first WD-repeat protein to be characterized by X-ray crystallography [34]. Since then various other crystal structures have been reported for WDrepeat proteins $[35,36]$ which include the recently determined structures for several RACK1 proteins, RACK1A from A. thaliana, Asc1p from S. cerevisiae, RACK1 from T. thermophila and RACK1 from human [37-41]. These structural studies confirmed the seven-bladed $\beta$-propeller structure. In the RACK1 structure each propeller blade consists of a four-stranded antiparallel $\beta$-sheet, where strand A lines the central canal of the protein, and strand $\mathrm{D}$ is present on the outer circumference. Adjacent blades are connected by a loop bridging from strand $\mathrm{D}$ on one blade to strand A on the next. These loops are exposed on the top face of the propeller blade as are the $\beta$-turns linking strands $B$ and $C$ in each blade. The loops connecting strand $A$ to $B$ and strand $C$ to $D$ in each blade are located on the reverse, slightly larger face of the propeller [31]. Most notably, the D-A loop between blades 6 and 7 in the RACK1 species is 8 to 19 residues longer than the cognate region of $G \beta_{1}$ and forms a knob-like projection from the upper face of the propeller (discovered in the crystal structure of A. thaliana RACK1A) [31]. This sequence is quite 


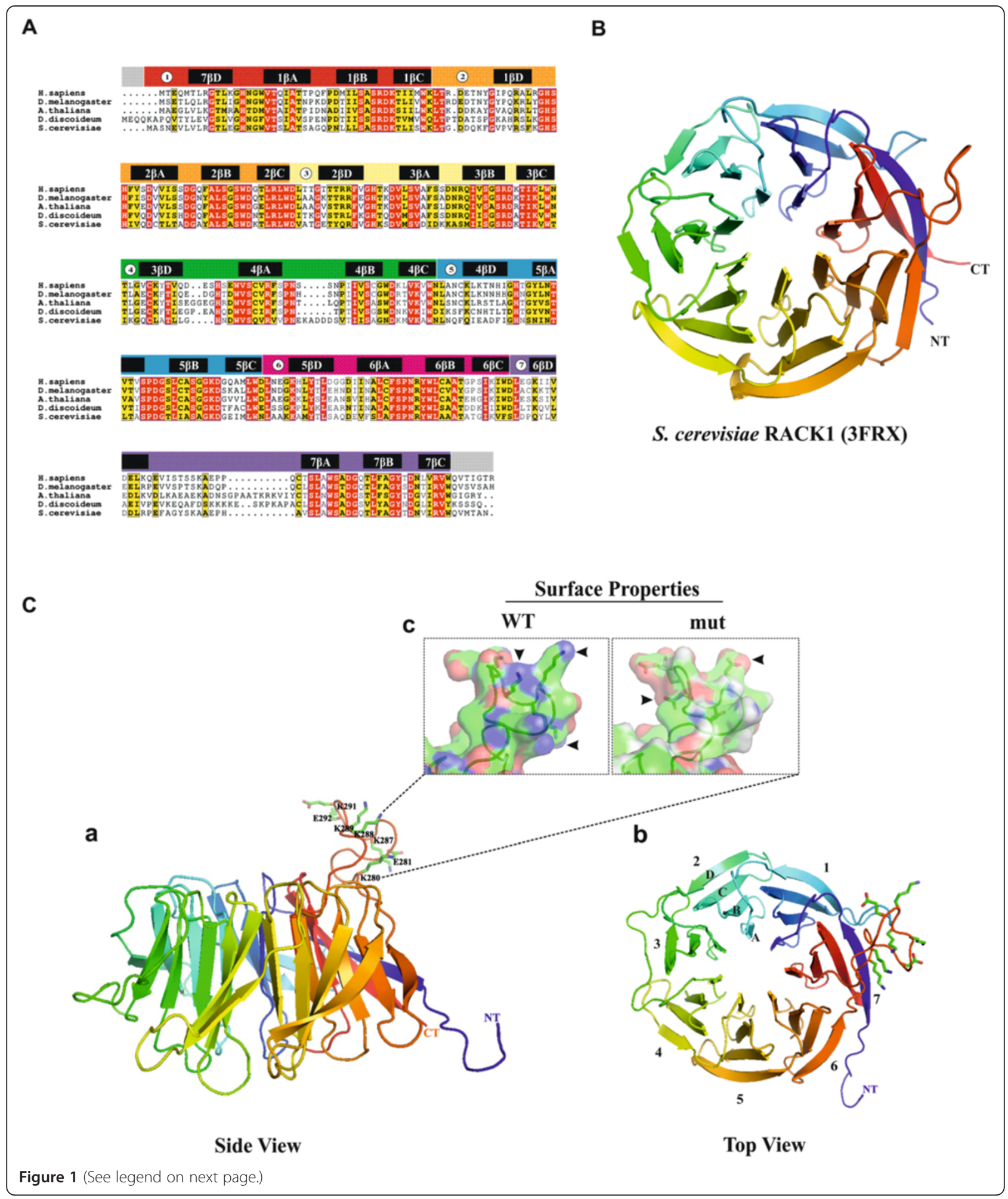


(See figure on previous page.)

Figure 1 Structure of RACK1 proteins. (A) Sequence alignment of RACK1 orthologues and their UniProt accession numbers from $H$. sapiens (P63244), D. melanogaster (O18640), A. thaliana (O24456), D. discoideum (DdRACK1) (P46800) and S. cerevisiae (P38011). The WD40 repeats and $\beta$ propeller blade positions are written above the sequences. Alignment was done with the ClustalW program and processed through ESPript for representation. All conserved residues are shown in red and similar residues in yellow. (B) Ribbon diagram of S. cerevisiae RACK1 (Asc1p) (PDB: 3FRX) which was used as template for DdRACK1 model. Shown are the seven $\beta$-propeller blades. Coordinates were retrieved from protein data bank (PDB) (www.rcsb.org) and modelled with the aid of MODELLER v9 program and visualized by the software PyMOL. (C) Ribbon structure of DdRACK1 (DDB0185122) showing (a), the side view of the $\beta$-propeller blades with some of the residues in the extended loop between blades 6 and 7 shown in ball and stick model, (b) the top view of the $\beta$-propeller blades with the same extended loop as in (a), and (c) the surface properties of DdRACK1 (WT) and DdRACK1mut (mut). Arrowheads pointing to blue and red regions indicate non-mutated and mutated residues, respectively. Structures were modeled and generated with the aid of MODELLER v9 program and visualized using molecular visualization software PyMOL.

unusual in the $D$. discoideum protein as it is rich in lysine residues. The general features described for RACK1 proteins are also present in DdRACK1 when we modelled the DdRACK1 sequence to the crystal structure of $S$. cerevisiae RACK1 (Asc1p) which reveals a comparable structure (Figure 1B, C).

\section{Subcellular distribution and developmental expression pattern of DdRACK1}

When we expressed RFP-DdRACK1 in AX2 cells expressing the $G$ protein beta-subunit as GFP-fusion protein for labeling the plasma membrane we found the protein present throughout the cytosol. A similar cytosolic RACK1 distribution was obtained when immunofluorescence studies were performed with AX2 cells stained with antibodies against DdRACK1 and actin for labeling the cell cortex (Figure 2A,B). On the other hand, immunofluorescence studies with aggregation competent AX2/GFP-Gß cells stained with anti-DdRACK1 antibodies showed RACK1 enrichment at the cell periphery and also in cell protrusions (Additional file 1: Figure S1, S2 (arrow)). Interestingly, in highly polarized cells, DdRACK1 was enriched at the leading edge (Additional file 1: Figure S3, arrow).

In cell fractionation assays a significant amount of DdRACK1 was present in both the cytosolic and the pellet fraction. GFP-DdRACK1 and GFP-DdRACK1mut were also relatively present in pellet fractions. $\alpha$-Actinin which served as cytosolic marker protein was exclusively present in the cytosolic fraction (Figure 2C). A membrane association of RACK1 is not surprising as it has been repeatedly found in phagosomal preparations from mouse and Drosophila, and GpbB has been found in phagosomal preparations from $D$. discoideum [42-45]. A developmental analysis showed the presence of DdRACK1 protein in nearly unaltered levels during all stages of Dictyostelium development (Figure 2D).

\section{Oligomerization potential of DdRACK1}

It has been suggested that RACK1 can dimerize in vivo and this dimerization is required for specific processes including the regulation of the $N$-methyl-D-aspartate
(NMDA) receptor by the Fyn kinase in the brain $[46-48,39,37]$. Here, we tested the capability of DdRACK1 to oligomerize using recombinant DdRACK1 full length protein that had been cleaved from the GST part. In the presence of the cross-linking reagent glutaraldehyde (0.001\%), DdRACK1 formed dimers and even higher oligomers with increasing time of incubation as detected by western blots using anti-DdRACK1 polyclonal antibodies. Interestingly, the native non-crosslinked DdRACK1 sample also contained some amount of dimers and oligomers (Figure 3A). This indicates that the dimerization characteristic exhibited by RACK1 proteins also holds true for DdRACK1. Similarly, DdRACK1mut also displayed wild type DdRACK1 oligomerization capability (Figure 3B). We further confirmed DdRACK1 dimerization by coimmunoprecipitation assays. Both GFP-DdRACK1 and GFP-DdRACK1mut bound to GFP-trap beads precipitated endogenous DdRACK1 (Figure 3C). AX2 cell lysates incubated with GFP-trap beads were used as control. Also, neither GFP bound to GFP-trap beads nor RFP bound to RFP-trap beads precipitated endogenous DdRACK1 (Figure 3C).

\section{Post-translational modification of DdRACK1}

Little is known about post-translational modifications of RACK1 apart from phosphorylation which is emerging as an important factor that modulates the binding of proteins to RACK1. Phosphorylation of specific tyrosine residues and their corresponding functions has been reported [31,49-54]. To determine if DdRACK1 also possesses the potential of becoming phosphorylated, we enriched DdRACK1 by immunoprecipitating GFPDdRACK1 from cell lysates that were prepared in the presence or absence of phosphatase inhibitor cocktail (PIC) and performed a western blot analysis using phosphotyrosine specific mAb 5E7 antibodies [55]. These antibodies recognized the GFP-DdRACK1 band on the blot indicating that DdRACK1, like RACK1 proteins from other species, can be phosphorylated on specific tyrosine residues (Figure 3D). AX2 cell lysate incubated with GFP-trap beads which was used as control showed no band. 
A

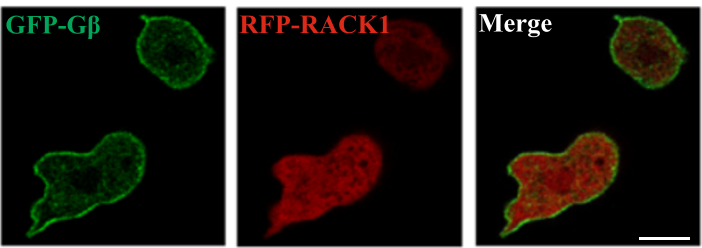

B
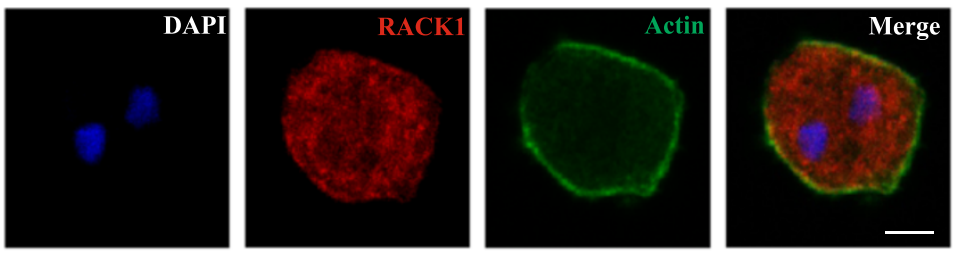

C

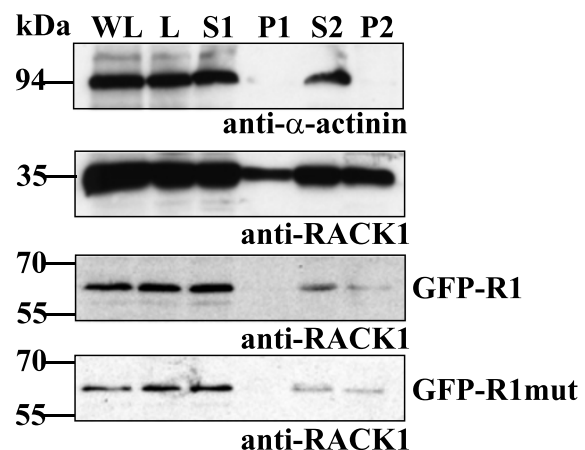

D

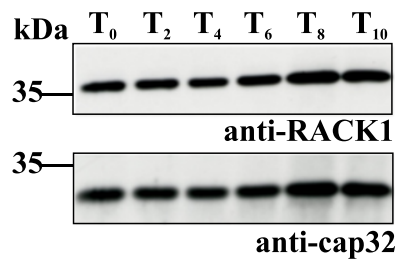

Figure 2 Subcellular localization, and developmental level of expression of DdRACK1. (A) To determine the localization of DdRACK1, AX2 wild type cells co-expressing GFP-GB and RFP-DdRACK1 were used to perform confocal live cell microscopy. (B) Immunofluorescence studies of AX2 wild type cells. Vegetative cells were fixed and stained with anti-DdRACK1 antibodies. mAb act1-7 against actin was used to visualize the cell cortex. Scale bar, 5 m. (C) Subcellular fractionation of AX2 and AX2 expressing GFP-DdRACK1 and GFP-RACK1mut after lysis by passing through Nucleopore filters. Protein aliquots separated by SDS PAGE were used to perform western blot analysis. WL, whole cell lysate; $L$, supernatant from cell lysate $(400 \times$ g); S1, P1 $(10,000 \times$ g); S2, P2 $(100,000 \times$ g). S, supernatant; P, pellet. DdRACK1 and relative amount of GFP-DdRACK1 and GFP-DdRACK1 mut were detected in supernatant as well as in pellet samples with polyclonal anti-DdRACK1 antibodies. mAb 47-16-8 detected the cytosolic marker protein a-actinin which served as control. The a-actinin blot for AX2 is shown. (D) DdRACK1 expression levels during development. Western blot analysis was performed with AX2 wild type cell samples collected during starvation in shaking suspension at indicated time points. DdRACK1 was detected with polyclonal anti-DdRACK1 antibodies. For loading control the blot was probed with mAb 188-19-95 which detects cap32.

\section{Lipid interactions}

The mechanism of membrane association of DdRACK1 is not known. In general, membrane association of proteins can be achieved by various mechanisms. For instance, polybasic clusters as defined by arginine- and lysine-enriched amino acid sequences enable diverse transmembrane and cytosolic proteins to bind lipids [56]. Also, proteins can target specific membranes through an interaction with phosphoinositides (PIPs). Based on the initial characterization of RACK1 as an interactor of RpkA, we tested the ability of DdRACK1 to bind to different phosphoinositides in vitro using GSTDdRACK1 in dot-blot (PIP strips) overlay assays. Whereas GST alone showed no PIP binding, GST-DdRACK1 bound with almost the same affinity to all the monophosphorylated PIPs, except for PI (3) P for which we observed stronger binding, to the bisphosphorylated PIPs as well as to the triphosphorylated PIP. GST-DdRACK1 also bound to phosphatidylserine (Figure 4A).

Although dot-blot overlay assays are convenient assays, they need to be supported by different methods as apparent specificities may be distorted and as they do not allow reliable quantification [57]. We therefore examined the sedimentation of GST-DdRACK1 with liposomes containing $65 \%$ phosphatidylcholine, $20 \%$ phosphatidylethanolamine, 5\% phosphatidylserine, reconstituted with $10 \%$ individual phosphoinositides. Although without any specificity, GST-DdRACK1 showed significant binding to 


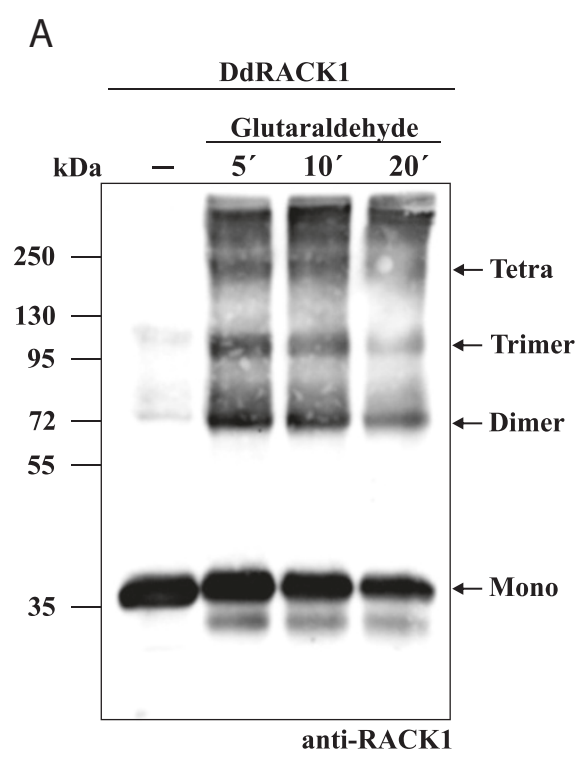

C

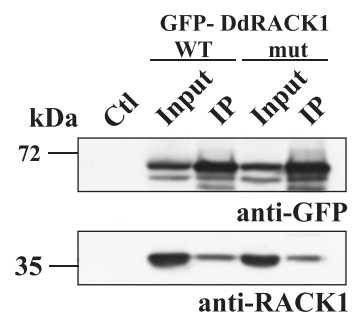

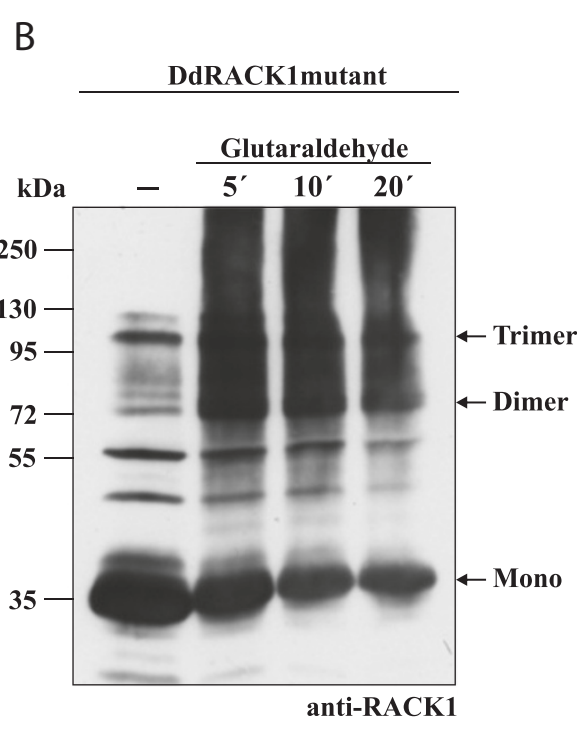

D

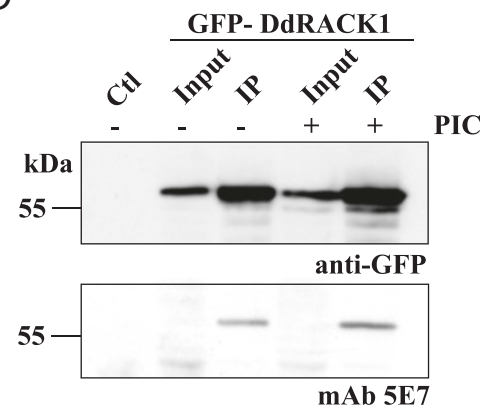

Figure 3 DdRACK1 forms homodimers and oligomers and is a phosphotyrosine-containing protein. (A) and (B) Analysis of DdRACK1 dimerization ability. 5-10 $\mu \mathrm{g} / 100 \mu \mathrm{l}$ of recombinant DdRACK1 (A) and DdRACK1mut (B) were incubated with $0.001 \%$ of the cross-linker glutaraldehyde and samples taken at the indicated time points of 5, 10 and $20 \mathrm{~min}$. For both DdRACK1 and DdRACK1 mut, in the absence of glutaraldehyde, the monomers (36 kDa, mono), including dimers $(72 \mathrm{kDa})$, and trimers (108 kDa) were detected. Protein bands which correspond to tetramers were also detected for DdRACK1. Proteins were detected with polyclonal anti-DdRACK1 antibodies. (C) Co-immunoprecipitation analysis using GFP-DdRACK1 and GFP-DdRACK1 mut. Both GFP-DdRACK1 and GFP-DdRACK1 mut bound to GFP-trap beads (upper panel) were able to immunoprecipitate endogenous RACK1 (lower panel). For GFP-RACK1 fusions, degradation bands were observed. GFP-trap beads incubated with AX2 wild type cell lysate was used as control (Ctl). (D) Detection of DdRACK1 as a phosphotyrosine-containing protein. Western blot analysis was performed with proteins from immunoprecipitated GFP-DdRACK1 cell lysates (upper panel) prepared in presence $(+)$ or absence $(-)$ of phosphatase inhibitor cocktail (PIC). AX2 cell lysate incubated with GFP-trap beads was used as control (Ctl). The phosphotyrosine specific mAb 5E7 detected GFP-DdRACK1 in the IP (lower panel).

these liposomes indicating a broad binding specificity for membranes. GST was included as a control and did not sediment with the liposomes (Figure 4B). To quantitatively study to which PIPs DdRACK1 preferably bound, band intensities of the Coomassie blue stained gels were scanned and the pellet fractions plotted. This assay showed that DdRACK1 interacted equally well with all the different PIPs (Figure 4C).

The A. thaliana and $D$. discoideum RACK1 proteins carry an insertion between propeller blades 6 and 7, which contains primarily basic amino acids, in case of DdRACK1 six lysine residues (Figure 1A,C). By charge-reversal mutation analysis, the lysine residues (-KKKK-) were replaced with glutamic acid to generate a GST fusion mutant version of DdRACK1 (GST-DdRACK1mut). The mutant protein was used in dot-blot protein overlay assays where it still bound to PI $(4,5) \mathrm{P}_{2}$ and PI $(3,4,5) \mathrm{P}_{3}$, whereas binding to all other PIP variants was completely abolished (Figure 4A). In liposome sedimentation assays GST-DdRACK1mut did not show significant binding to any of the PIPs, which support the requirement of this polybasic region for lipid binding (Figure 4B, C).

\section{DdRACK1 interacts with $\mathrm{G}$ proteins}

Conventional $G \beta$ subunits exhibit a high affinity for $\mathrm{G} \gamma$ subunits and function as $\mathrm{G} \beta \gamma$ heterodimers to bind and 
A

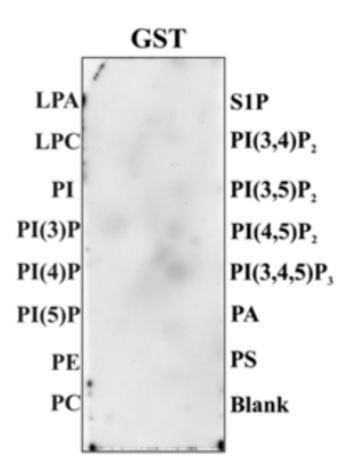

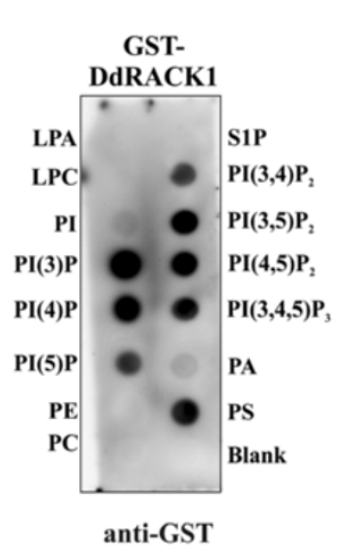

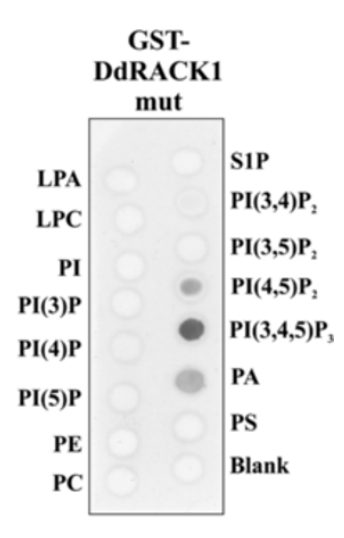

B

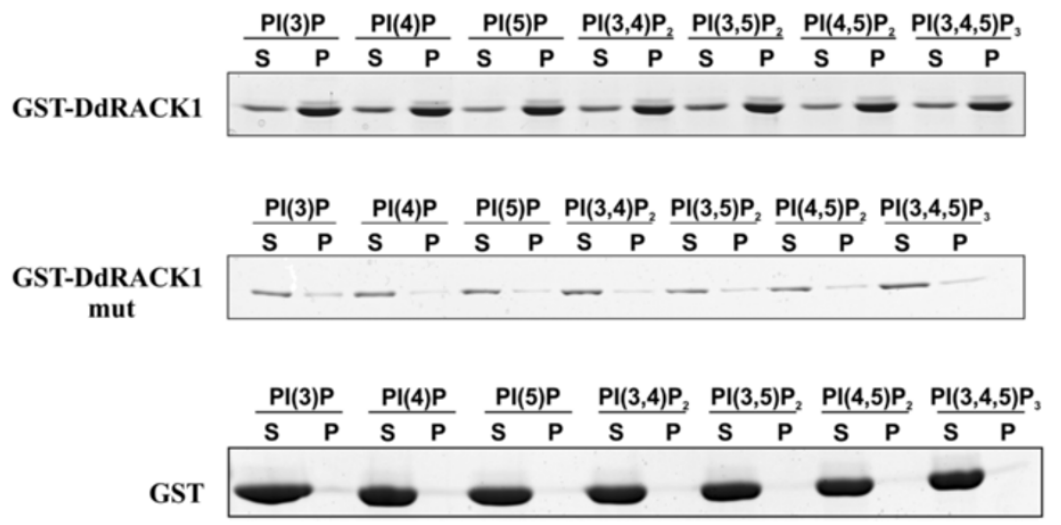

C

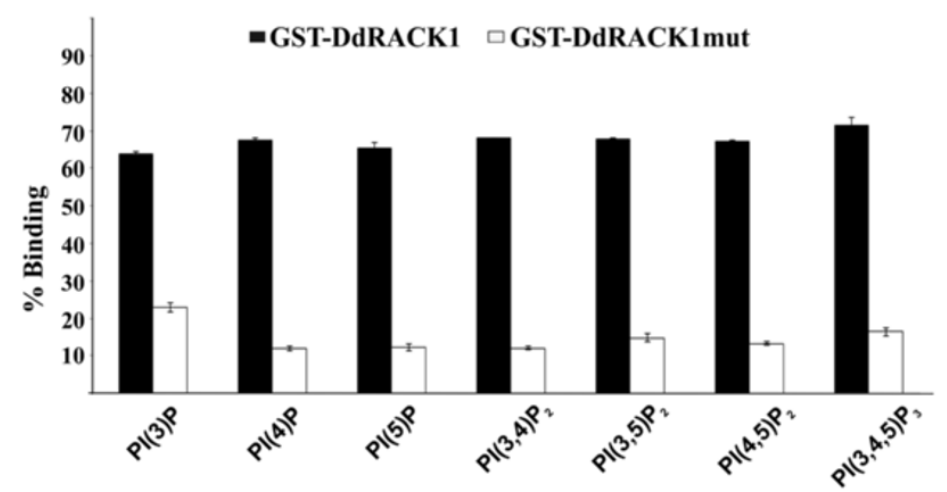

Figure 4 DdRACK1 binds to phosphoinositides. (A) PIP-Strip-membranes were incubated for $1 \mathrm{~h}$ at room temperature with $1 \mu \mathrm{g} / \mathrm{ml} \mathrm{GST}$ (control), GST-DdRACK1 and GST-DdRACK1mut, respectively. Binding to PIPs on membranes was detected by incubation with polyclonal anti-GST antibodies. (B) Binding of GST-DdRACK1, GST-DdRACK1 mut and GST (control) to PIPs in a liposome binding assay. 5-10 $\mu \mathrm{g}$ of GST and the GST-fusion proteins were incubated with liposomes containing 10\% (wt/wt) of the indicated PIPs. Liposomes were collected by centrifugation, and bound proteins resolved by SDS-PAGE and detected by Coomassie Blue staining ( $\mathrm{S}=$ supernatant; $\mathrm{P}=$ pellet). (C) Quantification of bound GST-DdARCK1 and GST-DdRACK1mut in pellet samples from (B). Protein bands were quantified with ImageJ software.

stabilize GDP-bound G $\alpha$ subunits. In addition, a G $\beta$ can associate with multiple individual Gy subunits [4]. The interaction of G $\beta \gamma$ with RACK1 was first identified by a yeast two-hybrid screen using the bovine $G \beta 1$ sequence as bait to screen a mouse brain library [26]. To test whether DdRACK1 likewise associates with the $D$. discoideum $\mathrm{G} \beta$ and $\mathrm{G} \gamma$ protein subunits, we performed a yeast two-hybrid analysis using DdRACK1 fused to the pACT2-AD. G $\beta$ and $G \gamma$ subunits were fused to pAS2$\mathrm{BD}$, respectively. We detected interactions between 


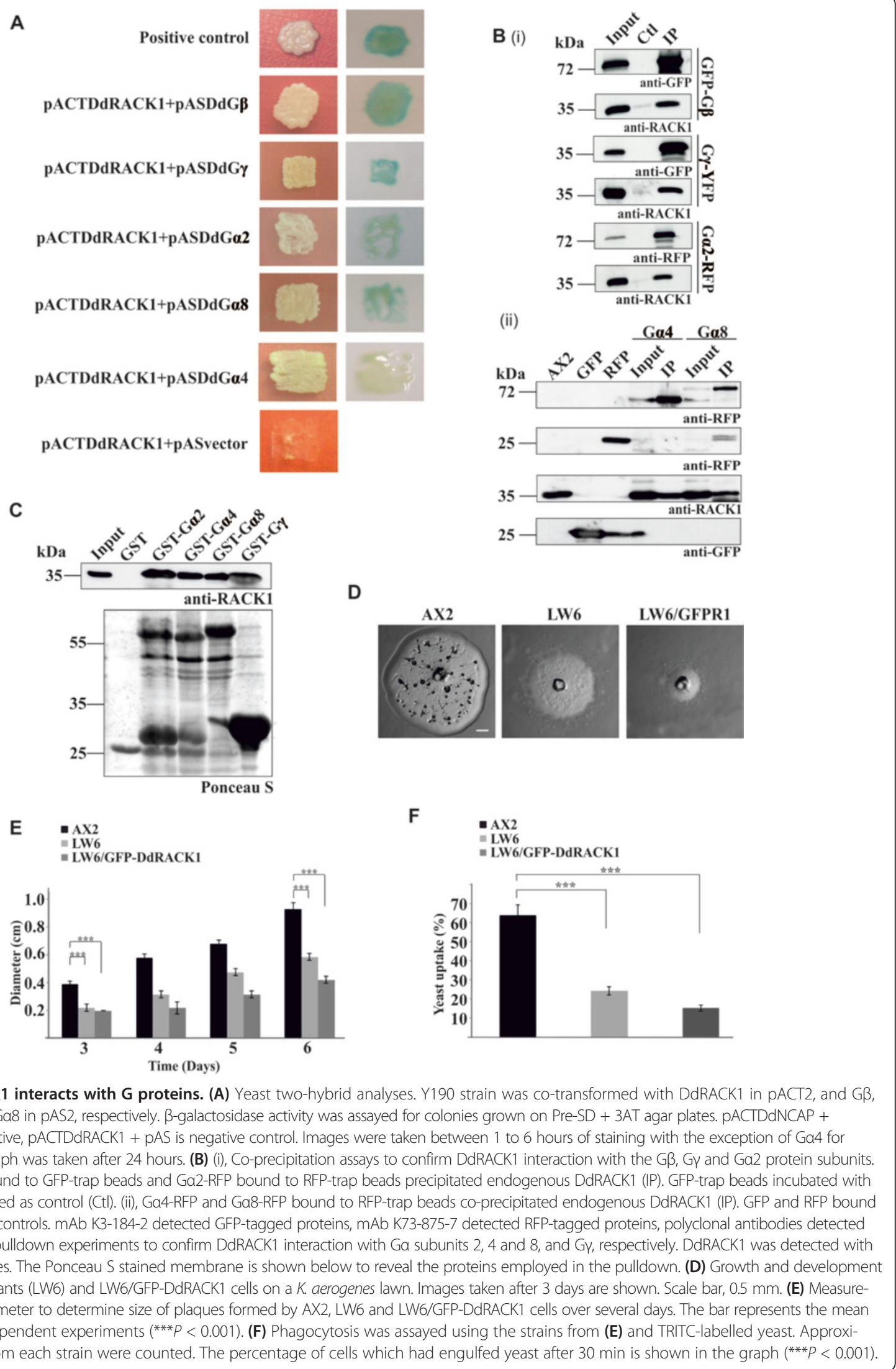


DdRACK1 and G $\beta$ as well as between DdRACK1 and Gy subunits as revealed by $\beta$-galactosidase production (Figure 5A, blue staining of the colonies). Colonies from yeast transformed with pACTDdRACK1 and pAS vector did not grow on the selection plates. To confirm these interactions we performed co-immunoprecipitation analyses. GFP-G $\beta$ as well as Gy-YFP from AX2/GFP-G $\beta$ and $\mathrm{AX} 2 / \mathrm{G} \gamma$-YFP cell lysates, respectively, which were bound to GFP-trap beads, were able to independently co-immunoprecipitate endogenous DdRACK1 (Figure 5B (i)). AX2 wild type cell lysate incubated with GFP-trap beads was used as control (Ctl). GFP and RFP bound to beads did not immunoprecipitate DdRACK1 either (Figure 5B (ii)). This provides further evidence that DdRACK1 resembles RACK1 proteins and, like those, interacts with $G \beta$ and $G \gamma$ subunits.

For S. cerevisiae it is reported that the RACK1 orthologue Asc1p functions as a $G \beta$ subunit for a $G \alpha$ (Gpa2) [30]. Similarly, in the human pathogenic fungus $C$. neoformans the RACK1 orthologue Gib2 functions as G $\beta$ for Gpa1 [29]. Like D. discoideum both organisms have a single G $\beta$ gene. To investigate DdRACK1-G $\alpha$ interactions, yeast two-hybrid assays were performed using

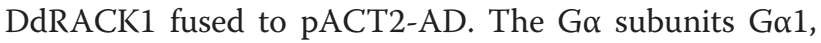
$\mathrm{G} \alpha 2, \mathrm{G} \alpha 4, \mathrm{G} \alpha 5, \mathrm{G} \alpha 6, \mathrm{G} \alpha 7, \mathrm{G} \alpha 8, \mathrm{G} \alpha 9, \mathrm{G} \alpha 10, \mathrm{G} \alpha 11$ and Go12 were fused to pAS2-BD. In these assays, we detected stronger interactions between DdRACK1 and

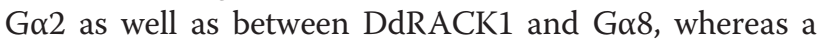
weak interaction was detected between DdRACK1 and Ga4 as concluded from the $\beta$-galactosidase staining assay (Figure 5A). Colonies from DdRACK1 interaction with the other $G \alpha$ subunits analyzed did not grow on selection plates (Additional file 1: Figure S4). The DdRACK1 interactions with $G \alpha 2,4$ and 8 were further confirmed in co-immunoprecipitation and pulldown

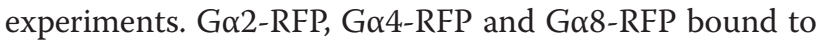
RFP-trap beads immunoprecipitated DdRACK1 from AX2 cell lysates, respectively (Figure 5B (i, ii)). Furthermore, GST-G $\alpha 2$, GST-G $\alpha 4$, GST-G $\alpha 8$ as well as GST-G $\gamma$ pulled down endogenous DdRACK1 whereas GST did not (Figure 5C).

To analyze if DdRACK1 also takes over the G $\beta$ function for the $G \alpha$ subunits in vivo, we ectopically expressed DdRACK1 as a GFP fusion in the $g \beta$ null mutant LW6 $[12,18]$ and analyzed whether it rescues the phagocytosis, chemotaxis, aggregation and developmental defects. We found that expression of GFP-DdRACK1 in LW6 cells did not rescue the developmental defect. When we plated the cells on a lawn of $K$. aerogenes, they formed smooth plaques as observed for the mutant strain. Remarkably the plaque size was even further reduced when we compared the AX2, LW6 and LW6/ GFP-RACK1 strains (Figure 5D,E). This might be due to a further reduction in the rate of phagocytosis or enhanced defects in cell motility. Hence we examined their phagocytic capability following yeast particle uptake and found that whereas fewer LW6 cells had ingested one or more yeast particles after $30 \mathrm{~min}$ as expected when compared with AX2 cells, even fewer LW6/GFP-DdRACK1 cells took up yeast cells. Quantitatively, $\sim 24 \%$ LW6 and $\sim 15 \%$ LW6/GFP-DdRACK1 strains had taken up yeast cells as compared to $\sim 64 \%$ uptake level for AX2 (Figure 5F). We conclude that G $\beta$ functions are not taken over by RACK1 upon ectopic expression in $D$. discoideum.

Dictyostelium cells display an amoeboid type of cell motility. We performed single cell random migration assays with growth phase AX2, LW6 and LW6/GFPDdRACK1 strains. Cells from all strains displayed similar motility with a speed of $6.62 \pm 1.85 \mu \mathrm{m} / \mathrm{min}$ (AX2), $6.54 \pm 3.53 \mu \mathrm{m} / \mathrm{min}$ (LW6) and $6.34 \pm 1.95 \mu \mathrm{m} / \mathrm{min}$ (LW6/GFP-DdRACK1), respectively.

\section{Growth and development of $D$. discoideum strains}

Our attempts to generate either $D$. discoideum knockout and/or knockdown mutants for RACK1 using different molecular biology techniques were not successful. Since RACK1 acts as a scaffold protein, interference with its levels might lead to cellular defects which give an indication about its involvement in critical cellular roles. Knowing fully well that an overexpression of RACK1 has effects on various cell types [58-61], we therefore tried to also study the effects of RACK1 overexpression in a wild type background and characterized AX2 cells expressing GFP-DdRACK1 and GFP-DdRACK1mut. In western blot analysis with AX2, AX2/GFP-DdRACK1 and AX2/GFP-DdRACK1mut cells, we found that the levels of RACK1 with respect to GFP-RACK1 and endogenous RACK1 were only moderately enhanced ( $17 \%$ in AX2/GFP-DdRACK1 and $~ 13 \%$ in AX2/GFPDdRACK1mut cells, respectively) when the blot was probed with anti-DdRACK1 polyclonal antibodies (Figure 6A). Such a behavior may be the result of the scaffolding function. It has been proposed that the levels of scaffold proteins should be tightly regulated as misregulation might interfere with many cellular processes [62].

Growth in shaking suspension was comparable between AX2 and AX2 expressing GFP-DdRACK1 and GFP-DdRACK1mut with similar duplication times and similar final densities $\left(\sim 1 \times 10^{7} \mathrm{cells} / \mathrm{ml}\right)$. However, once the cells had reached maximum density, AX2/GFPDdRACK1 and AX2/GFP-DdRACK1mut cells did not stay in the stationary phase for long like AX2 as cell counts dropped rapidly (Figure 6B). Differences were also observed during growth on lawns of $K$. aerogenes on SM agar and E. coli B12 on nutrient agar (NA) plates. In these assays we noticed an expanded growth zone containing AX2/GFP-DdRACK1 amoebae when they 


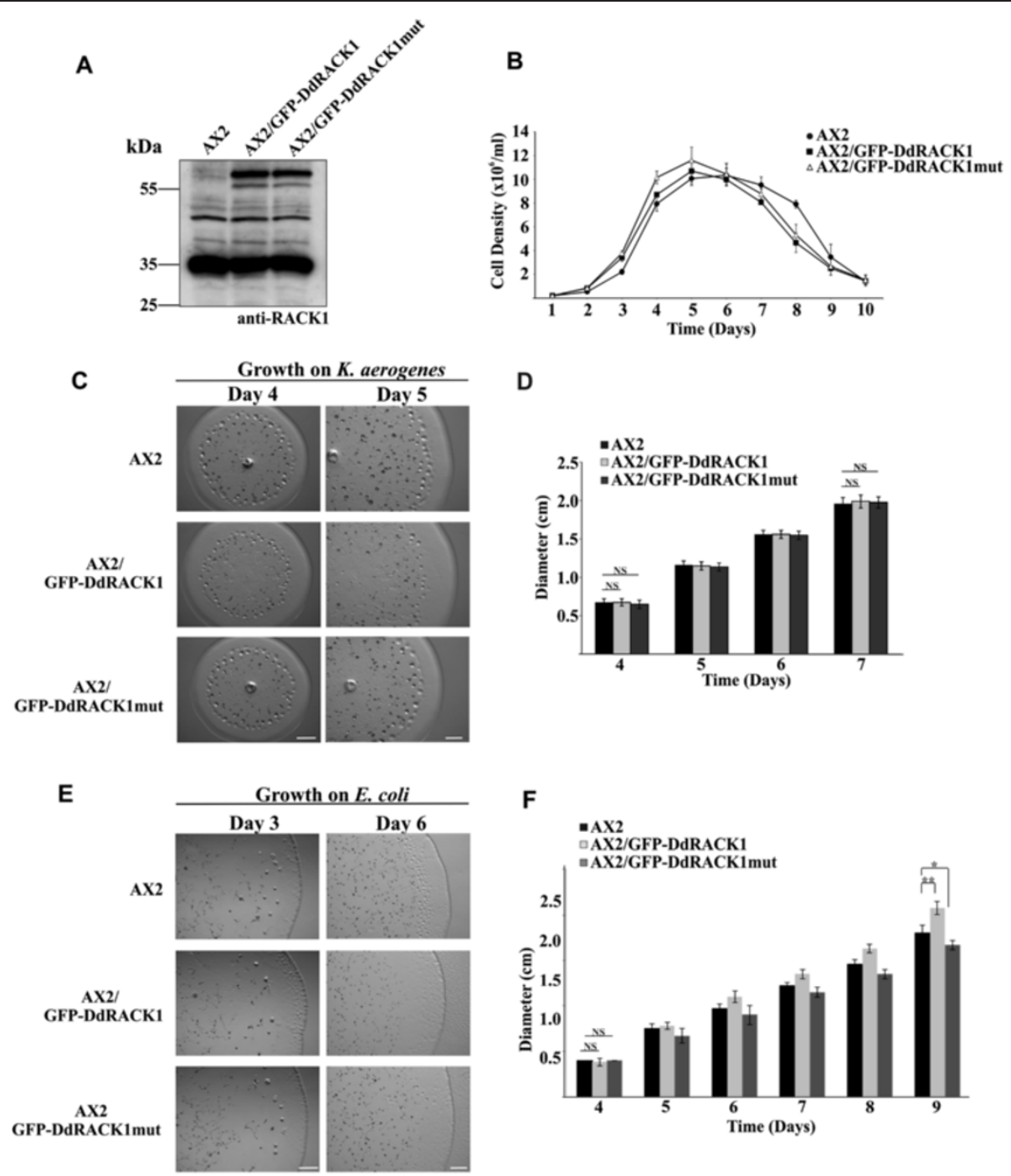

Figure 6 D. discoideum cells overexpressing DdRACK1 have growth and developmental defects. (A) Levels of DdRACK1 overexpression. Cell lysates from vegetative AX2, AX2/GFP-DdRACK1 and AX2/GFP-DdRACK1 mut strains were analyzed by SDS-PAGE and western blot. DdRACK1 and GFP-fusion proteins at 36 and $66 \mathrm{kDa}$ were detected with polyclonal anti-DdRACK1 antibodies. (B) Growth in shaking suspension of D. discoideum strains. $5 \times 10^{4} \mathrm{cell} / \mathrm{s} / \mathrm{ml}$ were used for inoculation. (C) Growth of $D$. discoideum strains on lawns of K. aerogenes. Images were taken on days 4 and 5. Scale bar, $1 \mathrm{~mm}$. (D) Bar chart showing diameter of plaques formed by D. discoideum strains in (C) measured between days 4 and 7. The bar represents the mean and SD of ten independent experiments (NS, not significant; $P>0.05$ ). (E) Growth of $D$. discoideum strains on lawns of $E$. coli B12 and imaged on days 3 and 6 . Scale bar, $1 \mathrm{~mm}$. (F) Bar chart showing diameter of plaques formed by $D$. discoideum strains in (E) measured between days 4 and 9. The bar represents the mean and SD of ten independent experiments $\left({ }^{*} P<0.01 ; * P<0.05\right.$; NS, not significant; $P>0.05$ ).

were grown on $K$. aerogenes when compared with AX2 (Figure 6C). Upon growth on lawns of E. coli B12 the behavior for AX2/GFP-DdRACK1 strain was conspicuously different from AX2 on day 3 (Figure $6 \mathrm{E}$ ). On $K$. aerogenes lawns, AX2 cells expressing GFP-DdRACK1mut were like wild type. AX2, AX2/GFP-DdRACK1 and AX2/GFPDdRACK1mut displayed similar growth rates on lawns of $K$. aerogenes when the plaque diameter was measured between days 4 and 7 (Figure 6D). On E. coli lawns however, the AX2/GFP-DdRACK1 strain showed a significantly higher growth rate after 9 days whereas AX2 showed slightly increased growth compared to AX2/GFP-
DdRACK1mut (Figure 6F). AX2 cells expressing GFP displayed growth behavior like AX2 wild type cells on a $K$. aerogenes lawn (Additional file 1: Figure S5). Faster growth on a bacterial lawn could be due to increased phagocytosis, altered cell motility or to a developmental defect.

Therefore we next analyzed development which is initiated by starvation. AX2 cells plated on phosphate agar plates start to form multicellular aggregates between 8 to 12 hours and have formed fully differentiated fruiting bodies after $\sim 24$ hours. In our experiments cells from all strains had gathered into mounds at 10 hours. After 24 hours AX2 and AX2/GFP cells had formed fruiting 
bodies, whereas those of both AX2/GFP-DdRACK1 and AX2/GFP-DdRACK1mut were still present as tight aggregates and fruiting bodies which were much smaller than those of AX2 were observed only after 42 hours. There were still many mounds present (Figure 7A).
To investigate development further, we examined the aggregation behavior of these strains on a plastic surface. AX2 cells were highly elongated and formed well-defined streams after 9 hours of starvation. After 11 hours the streams became thicker and shorter. AX2/GFP-DdRACK1

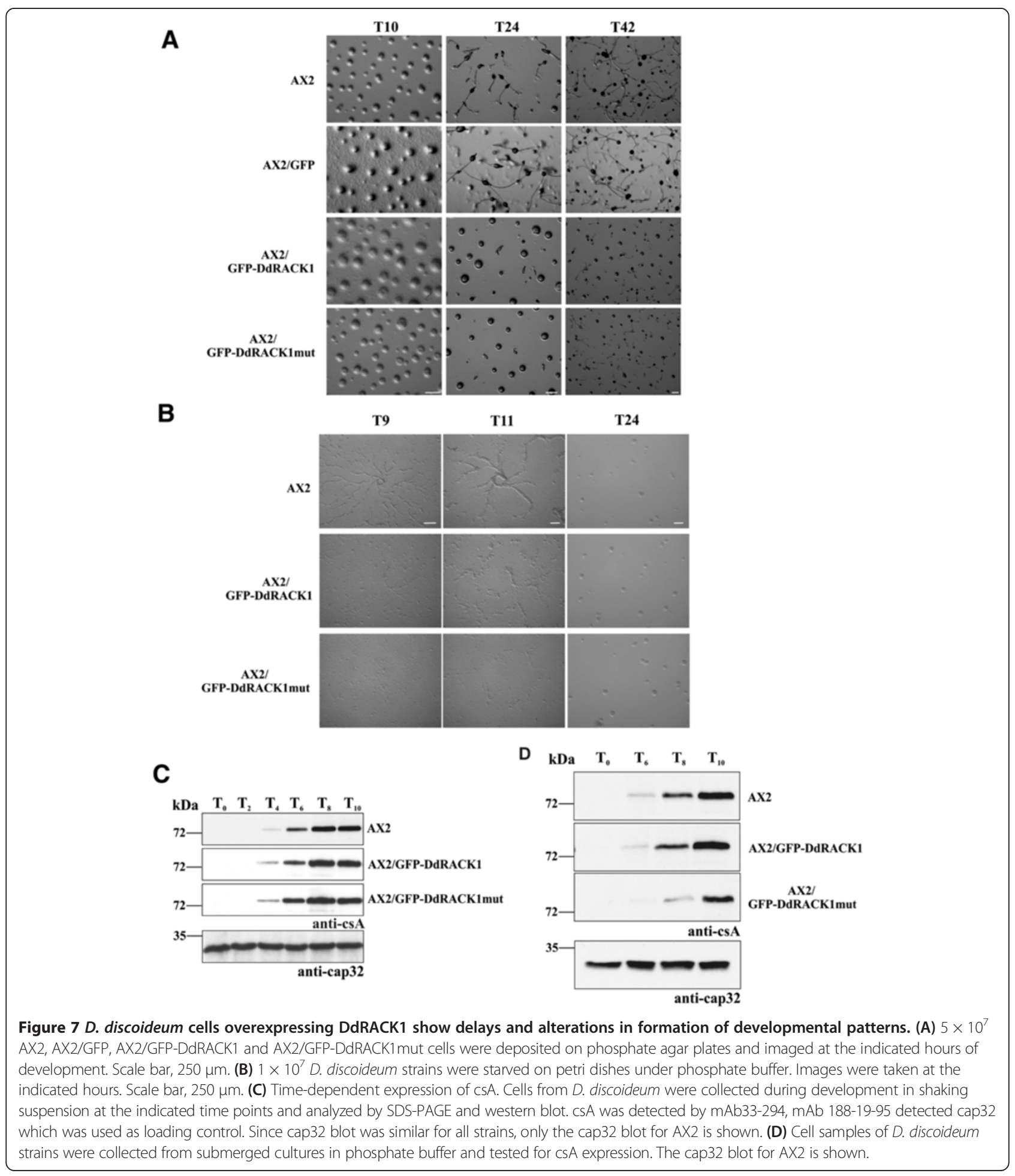


and AX2/GFP-DdRACK1mut cells failed to form streams after 9 hours. AX2/GFP-DdRACK1 cells started to stream and form aggregates after 11 hours. Start of aggregate formation was even more delayed in AX2/GFP-DdRACK1mut cells (Figure 7B). An aggregation experiment with AX2/GFP cells revealed the same developmental pattern as seen for AX2 (Additional file 1: Figure S6). When we monitored the expression of the strictly developmentally regulated cell adhesion protein contact site A (csA) in cells starved in shaking suspension, we observed a similar expression pattern with a first detection after four hours of starvation and a steady increase in all three strains (Figure 7C). This was however not the case when we monitored csA expression from cells starved on plates. In AX2 and AX2/GFP-DdRACK1 csA was first detected after six hours of starvation, AX2/GFP-DdRACK1mut cells showed delayed csA expression with first detection after eight hours of starvation (Figure 7D) supporting the data obtained by visual inspection (Figure 7B).

\section{Discussion}

Scaffold proteins uniquely integrate signals from multiple pathways. They generate lots of functional diversity by mediating a series of interactions with a vast array of protein partners. The receptor for activated $C$ kinase 1 (RACK1) is a member of the evolutionarily conserved family of WD40 repeat proteins which forms seven $\beta$ propeller blades. It was initially discovered through its ability to function as a scaffold protein, bringing in close proximity protein kinase $\mathrm{C}$ (PKC) and its substrates $[63,23]$. In this study we report a novel protein in $D$. discoideum that is hitherto uncharacterized and displays significant homology with RACK1 proteins that have been well studied in various other species. Due to its high similarity to these other RACK1 proteins, we have named this protein DdRACK1.

DdRACK1 is a WD40 repeat protein harboring a seven-bladed $\beta$-propeller that shares similarities with the heterotrimeric $\mathrm{G}$ protein $\beta$ subunit. The modelled structure of DdRACK1 features the seven $\beta$-propeller architecture with each propeller blade arranged in sequential order and made up of four-stranded antiparallel $\beta$ sheets. Although differences exist, particularly in the extended loop that connects $\beta$-propeller blades 6 and 7 , the structures of RACK1 from S. cerevisiae [40], A. thaliana [39] and human [41] show significant sequence identity with DdRACK1. The region between the $\beta$ propeller blades 6 and 7 is quite conserved between DdRACK1 and $A$. thaliana RACK1A. The major difference between the WD repeats is in the loops that provide the distinct features of each member of the WD family and distinguish RACK1 interactions from those of other WD proteins $[64,65]$. The A. thaliana protein was the first RACK1 orthologue to be structurally described [31]. Unlike in A. thaliana where RACK1 is expressed by three genes, DdRACK1 is expressed by only one gene, $g p b B$, as in metazoans. Two conserved surface regions of $A$. thaliana RACK1A have been proposed to represent protein-protein interaction sites [39]. The first region is located on the top rim of the propeller and involves side chains from residues R36, K38, S63, H64 (blade 1), R42, K44, S70, H71; W83, D107 (blade 2), W90, D114; R125 (blade 3), R132; and W152 (blade 4), W158 in DdRACK1. The second large conserved surface region of RACK1 is located on the bottom of the propeller and is comprised of conserved residues P204, D205, Y230 (blade 5), P208, D209, Y234; and N246, Y248 and W249 (blade 6), N250, Y252 and W253 in DdRACK1. Besides the high sequence identity between DdRACK1 and RACK1 from other species, the presence and conservation of these above mentioned regions indicates that DdRACK1 is a member of the RACK1 family of WD40 repeats proteins and may undergo similar interactions.

Although DdRACK1 is mainly cytosolic as seen from live confocal microscopy pictures, immunofluorescence and fractionation studies, a portion of it was also found in the membrane fraction, buttressing localization to cellular membranes by proteins of the RACK1 family. Furthermore, DdRACK1 was detected at the cell periphery and the leading edge of highly polarized aggregation competent cells. This implies that RACK1 regulates signal transduction at the leading edge. RACK1 is essential for cell migration, and the protein binds to many components of the cell migration machinery including kinases, phosphatases and the cytoplasmic domains of cell surface receptors $[65,66]$. RACK1 is located in areas of cell protrusios that are rich in paxillin $[67,68]$ and can increase the phosphorylation of FAK [68]. Furthermore, RACK1 has been reported to bind to components of the cytoskeleton [69,70]. Mutations in DdRACK1 did not seem to alter its localization to membranes as was observed from fractionation analysis in this study. One reason could be that it may have accompanied interaction partners to these sites.

RACK1 dimerizes both in vivo and in vitro $[40,41,46]$. The physiological role is however still unclear. In the regulation process of the NMDA receptor by Fyn, RACK1 dimerization is required to bring the two interacting partners in close contact. RACK1 dimerization allows exposing a new surface of the protein, buried within the propeller core in the monomeric form [46]. We have provided evidence that DdRACK1 also has the potential to dimerize. The dimerization of human RACK1 is enhanced by phosphorylation [47] and one of the putative phosphorylation sites was Ser146 in blade 3. This residue is however not conserved in DdRACK1, but there are other Ser/Thr residues present in this region which could probably be potential targets in 
mediating DdRACK1 dimerization by phosphorylation. On the other hand, an important factor which modulates the binding of RACK1 proteins to partners is tyrosine phosphorylation [31]. Phosphorylation/dephosphorylation of different tyrosine residues of human RACK1 regulates various cellular processes [49,50,71]. These tyrosine residues are also conserved in DdRACK1, and we provided evidence that the DdRACK1 protein is a phosphotyrosine-containing protein. However, this study did not associate the phosphorylation of DdRACK1 with a function.

Phosphoinositides (PIPs) regulate fundamental biological processes including cell growth and survival, membrane trafficking and cytoskeletal dynamics [72]. PIPs are tightly regulated during chemotaxis in $D$. discoideum, in particular, PI $(3,4,5)$ P3 gradients are formed within the plasma membrane [73]. They are thought to be of differing importance for sensing of shallow and steep gradients $[74,75]$. In the region between $\beta$ propeller blades 6 and 7 we noted a key polybasic cluster (-KKKK-) in DdRACK1 which turned out to be responsible for binding to several PIPs; PI (3) P, PI (4) P, PI (5) P, PI $(3,4)$ P2, PI $(3,5)$ P2, PI $(4,5)$ P2, and PI $(3,4,5)$ P3 without particular preference; and also to phosphatidylserine. The translocation of RACK1 from one subcellular location to another has been shown to mediate various cellular responses following a stimulus [25]. However, the mechanism of RACK1 localization to cellular membranes is not known. PIPs are clustered in distinct intracellular membranes and serve as marker for different organelles. We propose therefore that one way by which RACK1 localizes to different cellular membranes may be via its interaction with PIPs which in $D$. discoideum is mediated by the polybasic stretch. Whether RACK1 proteins from other species also interact with membrane lipids needs to be investigated.

G protein-linked signal transduction plays an essential role in the developmental program of Dictyostelium [76-78]. D. discoideum has twelve $G \alpha$ subunits, one $G \beta$ and one $\mathrm{G \gamma}$ subunit. It is generally assumed that $G \beta$ forms heterotrimers with the $\gamma$ and all $\alpha$ subunits [79]. For RACK1, interactions with $\mathrm{G}$ protein heterotrimer and heterodimeric $\beta \gamma$ subunits were reported [26-28]. We describe here an interaction of DdRACK1 with $\mathrm{G \alpha}$ subunits 2, 4 and 8 , as well as with the G $\beta$ and Gy subunits by yeast two-hybrid, co-immunoprecipitation and pull down experiments. Whereas $G \alpha$ subunits 2 and 4 are involved in chemotaxis, G $\alpha 8$ was recently shown to function in cell proliferation, adhesion and cell differentiation. It is not very clear why DdRACK1 selectively interacts with these Go subunits. However, RACK1 has been implicated in these cellular processes and the mutant phenotypes that we observed after overexpression revealed roles in cell growth and development. It further confers RACK1 with functions in the regulation of signaling processes in which these $\mathrm{G \alpha}$ subunits are involved (Figure 8). This also does not completely rule out the possibility of DdRACK1 interaction with the other Ga subunits which may be very weak to be detected by these approaches. Further studies still have to be done to determine structural mechanisms underlying DdRACK1 interaction with these $\mathrm{G} \alpha$ subunits.

\section{Conclusion}

We have identified the novel RACK1 orthologue in $D$. discoideum (DdRACK1) which has significant sequence

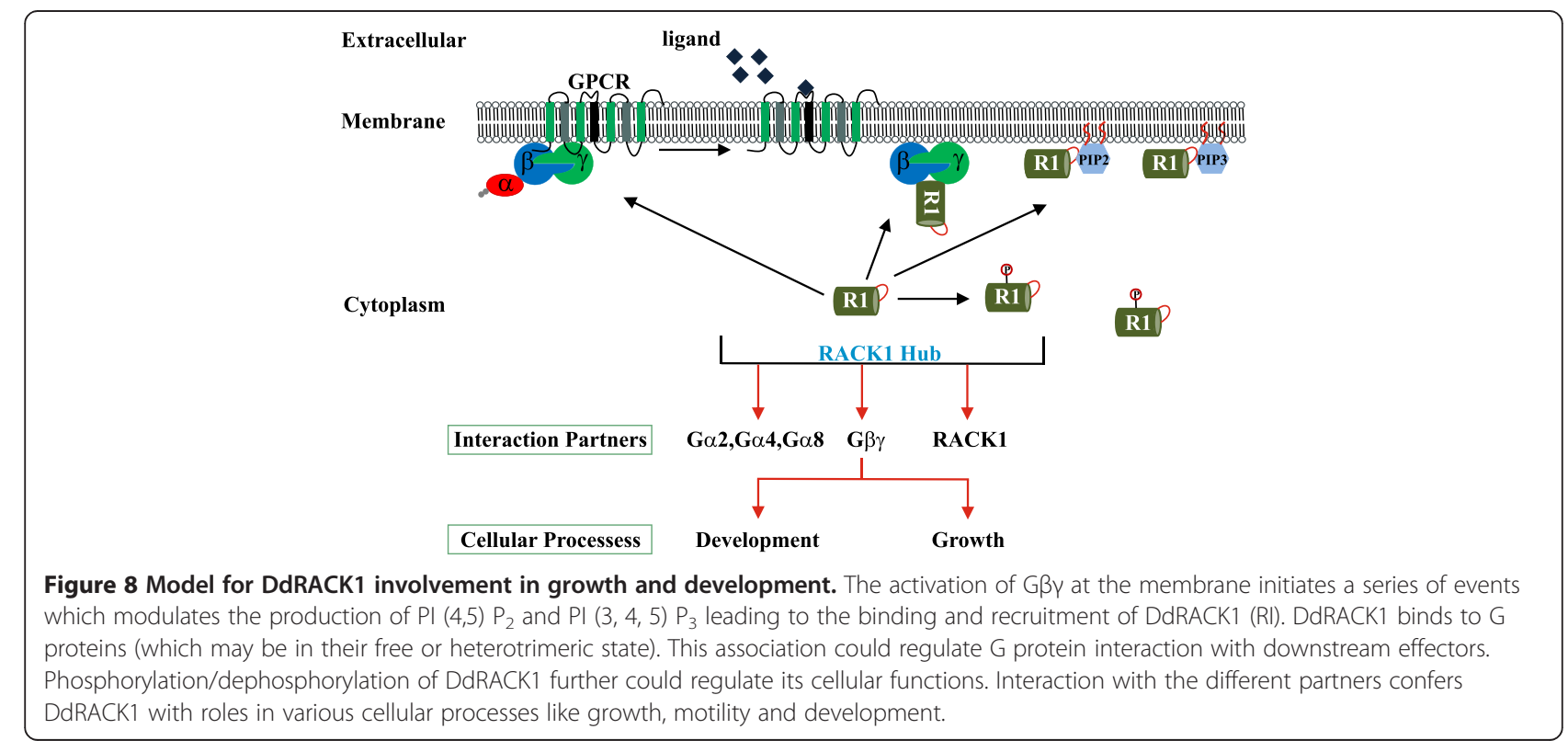


identity with other previously studied RACK1 species and similar biochemical features as bona fide RACK1 proteins. Together with the Arabidopsis protein it contains an unusual polybasic region through which it can bind to cellular membranes uncovering a further mechanism how RACK1 can be targeted to membranes. At the biochemical level it interacts with several proteins among them ribosomal proteins, enzymes, cytoskeletal proteins and most notably heterotrimeric G proteins. Upon overexpression we observe phenotypes that imply changes in signaling pathways regulated by the interacting $\mathrm{G}$ proteins. In summary (Figure 8 ), we propose that, through these interactions, RACK1 is involved in the regulation of several cellular processes.

\section{Materials and methods}

\section{Growth, development and transfection}

Cells were either grown on a lawn of $K$. aerogenes on SM agar plates, on a lawn of E. coli B12 on NA-agar or cultivated in shaking suspension $(160 \mathrm{rpm})$ or in a submerged culture at $21-23^{\circ} \mathrm{C}$ in axenic medium [80]. Development was initiated by plating $5 \times 10^{7}$ cells which were washed twice with Soerensen phosphate buffer (17 $\mathrm{mM} \mathrm{Na}^{+} / \mathrm{K}^{+}$phosphate, $\mathrm{pH}$ 6.0) on phosphate agar plates and monitored. Development was also followed for cells starved in Soerensen phosphate buffer in shaken suspension $\left(1 \times 10^{7}\right.$ cells $/ \mathrm{ml} ; 160 \mathrm{rpm}$ at $\left.22^{\circ} \mathrm{C}\right)$ or in petri dishes. Mutants were maintained in the presence of appropriate antibiotics $(2-4 \mu \mathrm{g} / \mathrm{ml} \mathrm{G418)}$ (Roche Applied Science) (or 3-5 $\mu \mathrm{g} / \mathrm{ml}$ Blasticidin) (MP Biomedicals Inc., Eschwege, Germany). The following strains have been used; AX2-214 (wild type) [81], AX2 expressing GFP-, YFP- or RFP-tagged fusion proteins, G $\beta$ null mutants LW6 [12] and LW6 expressing GFP-DdRACK1. The corresponding plasmids were introduced by electroporation using a Biorad electroporator Gene Pulser Xcell (Biorad, München, Germany) according to the protocol supplied.

\section{Cloning of RACK1 CDNA and expression of recombinant proteins}

For expression of recombinant $D$. discoideum RACK1 as glutathione $\mathrm{S}$ transferase (GST) fusion protein in E. coli, a full-length cDNA was cloned into pGEX-4 T-1 vector (GE Healthcare Life Sciences). E. coli strain XL1 Blue was used for expression of the GST fusion protein. Induction of protein expression was with $0.25 \mathrm{mM}$ isopropyl $\beta$-D-thio-galactoside (IPTG) when an $\mathrm{OD}_{600}$ of 0.8 was reached. Cells were further cultured at $30^{\circ} \mathrm{C}$ for 3 hours. They were harvested, lysed in $50 \mathrm{mM}$ Tris/ $\mathrm{HCl}$, $\mathrm{pH} 7.4$ to $8.0,100 \mathrm{mM} \mathrm{NaCl}$, supplemented with Protease inhibitors (0.5 mM PMSF, $1 \mathrm{mM}$ Benzamidine and Complete (Roche) and $1 \mathrm{mM}$ DTT) with an EmulsiFlex cell homogenizer (Avestin Europe GmbH, Mannheim,
Germany). Lysates were separated into soluble and insoluble fractions by centrifugation at $18,000 \times \mathrm{g}$. The fusion proteins from the soluble fraction were purified using GST-Sepharose beads (GE Healthcare).

For cleavage of proteins from GST-Sepharose beads, the GST fusion proteins were washed 5 times with cleavage buffer $(20 \mathrm{mM}$ Tris/ $\mathrm{HCl}, \mathrm{pH} 7.4,150 \mathrm{mM} \mathrm{NaCl}$ and $0.2 \%$ Sarcosyl). Beads were then resuspended in cleavage buffer and 3-10 U thrombin/mg fusion protein were added to the beads and incubated with little agitation at room temperature overnight. As RACK1 was released from the beads together with some GST, we next performed an anion exchange chromatography step in order to separate the proteins. For this the protein solution was dialyzed against $20 \mathrm{mM}$ Tris/ $\mathrm{HCl}, \mathrm{pH}$ 8.0, and $1 \mathrm{mM}$ EDTA overnight before loading onto a DE-52 Sephadex column which had been calibrated with $50 \mathrm{mM}$ Tris/ $\mathrm{HCl}, \mathrm{pH}$ 8.0, $1 \mathrm{mM}$ EDTA. The protein was eluted with $1 \mathrm{M} \mathrm{NaCl}$ and the eluate dialyzed and analyzed by SDS-PAGE.

For expression in AX2 the RACK1 cDNA was cloned into pBsr-N2-GFP vector (N-terminal GFP) and expressed as GFP-RACK1 under control of the actin 15 promoter and also into mRFPmars plasmid (N-terminal RFP) for RFP-RACK1 [82,83]. A PCR-mediated sitedirected mutagenesis (QuikChange Site-Directed Mutagenesis Kit, Stratagene) was used to generate mutations in the GST-RACK1 and GFP-RACK1 plasmids. The mutations were confirmed by sequencing.

\section{Phosphoinositide binding assay}

PIP-strips supplied by Echelon Biosciences, Inc. (Salt Lake City, Utah, USA) were used to perform phosphoinositide binding according to the supplied protocol. Briefly, GST and GST-fusion proteins were eluted from the glutathione agarose beads with elution buffer (20 mM reduced glutathione, $50 \mathrm{mM}$ Tris/ $\mathrm{HCl}, \mathrm{pH} 7.4$, $100 \mathrm{mM} \mathrm{NaCl}, 0.2 \%$ Tween-20, and $100 \mathrm{mM} \mathrm{DTT}$ ).

The membranes were blocked with $0.1 \%$ ovalbumin (Sigma \# A-5253) in TBS for one hour at room temperature. After discarding the blocking solution membranes were incubated with $1 \mathrm{mg} / \mathrm{ml}$ GST-fusion proteins in TBS-T $(50 \mathrm{mM}$ Tris/ $\mathrm{HCl}, \mathrm{pH} 7.4,100 \mathrm{mM}$ $\mathrm{NaCl}, 0.2 \%$ Tween-20) at room temperature for one hour. The protein solution was then discarded and the membranes were washed with TBS-T three times $10 \mathrm{mi}-$ nutes each. Bound protein was detected by western blot analysis with GST polyclonal antibodies as primary and anti-rabbit IgG-peroxidase (Sigma \# A-6154) as secondary antibody followed by enhanced chemiluminescence.

\section{Lipid vesicle preparation and sedimentation assay}

Phosphatidylserine (PS), phosphatidylcholine (PC), phosphatidylethanolamine (PE), PI (3) P, PI (4) P, PI (5) P, PI 
$(3,4)$ P2, PI $(3,5)$ P2, PI $(4,5)$ P2, and PI $(3,4,5)$ P3 were obtained from Sigma and diluted in chloroform. Liposome binding experiments were performed with a modified published liposome binding assay protocol [84]. Lipid mixtures containing 65\% PC, 20\% PE, 5\% PS and $10 \%$ individual phosphoinositides were produced by mixing appropriate lipid solutions in chloroform/methanol. Slow flow nitrogen gas was used for the production of a film on the glass and vacuum desiccation for $30 \mathrm{~min}$ for solvent removal. Sterile-filtered sucrose binding buffer (20 mM HEPES, pH 7.4, $100 \mathrm{mM} \mathrm{KCl,} 1$ mM EDTA, $0.1 \mathrm{M}$ sucrose) was added to a final lipid concentration of $1 \mathrm{mg} / \mathrm{ml}$ and incubated at $37^{\circ} \mathrm{C}$ for $2 \mathrm{~h}$. Lipids were then sonicated in a waterbath-sonicator for $10 \mathrm{sec}$. To test liposome binding, a $100 \mu \mathrm{l}$ reaction mixture of freshly prepared liposomes and $5 \mu \mathrm{g}$ of purified protein were incubated for $15 \mathrm{~min}$ at room temperature and centrifuged at $100,000 \times \mathrm{g}(42,000 \mathrm{rpm})$ at $4^{\circ} \mathrm{C}$ for $25 \mathrm{~min}$ in a Beckman table top ultracentrifuge Optima TLX (TLA 45 rotor). The supernatant was saved, and the pellet was resuspended in $100 \mu \mathrm{l}$ of sucrose binding buffer.

Both fractions were then analyzed by SDS-PAGE followed by Coomassie blue staining. ImageJ was used for quantification.

\section{Yeast two-hybrid interaction}

For the yeast two-hybrid screen, the full-length cDNAs of $D$. discoideum G protein $\beta-, \gamma^{-}, \alpha 1-, \alpha 2-, \alpha 4-, \alpha 5-, \alpha 6-$, $\alpha 7-, \alpha 8-, \alpha 9-, \alpha 10-, \alpha 11-$ and $\alpha 12$-subunits were cloned in frame into the yeast pAS2-1 vector (Clontech), respectively, resulting in fusion to the GAL4-DNA-BD (BD, binding domain). Full-length cDNA of DdRACK1 was cloned into the yeast pACT2 vector (Clontech) resulting in a fusion to the GAL4-DNA-AD (AD, activation domain). Yeast Y190 strain was used for this assay.

Candidate colonies expressing interacting proteins were screened by plating on SD/-Leu/-Trp/-His/+3AT plates after which membrane colonies-lift $\beta$-galactosidase activity assay was performed according to the MATCHMAKER Y2H system manual. Briefly, colonies on SD/Leu/-Trp/-His/+3AT selection plates were transferred to a Nitrocellulose membrane (Protran BA 85) by placing the membrane over colonies on selection plates for $20 \mathrm{~min}$. The filter was carefully lifted off the agar plates and transferred (with colonies facing up) to a pool of liquid nitrogen for $10 \mathrm{sec}$. The frozen filter was then allowed to thaw at room temperature and placed on a Whatman filter paper presoaked in freshly prepared X-Gal solution (60 $\mathrm{mM} \mathrm{Na} \mathrm{HPO}_{4}, 40 \mathrm{mM} \mathrm{NaH} \mathrm{PO}_{4}, 10 \mathrm{mM} \mathrm{KCl}$, $1 \mathrm{mM} \mathrm{MgSO}_{4}, \mathrm{pH} 7.0,50 \mathrm{mM} \beta$-mercaptoethanol, $\mathrm{X}-\mathrm{Gal}(1 \mathrm{mg} / \mathrm{ml}$ final concentration)) and incubated at $30^{\circ} \mathrm{C}$ and checked between 1 to $6 \mathrm{~h}$, and after $24 \mathrm{~h}$ (for detection of weak interactions) for the appearance of blue colonies.

\section{Pull down and immunoprecipitation assays}

For pull down and immunoprecipitation experiments $D$. discoideum cells were lysed in $50 \mathrm{mM}(10 \mathrm{mM}$ for immunoprecipitation assay) Tris/ $\mathrm{HCl}, \mathrm{pH} 7.4,150 \mathrm{mM}$ $\mathrm{NaCl}, 0.5 \% \mathrm{NP} 40$, supplemented with protease inhibitor cocktail (Sigma), $0.5 \mathrm{mM}$ PMSF, $0.5 \mathrm{mM}$ EDTA, and $1 \mathrm{mM}$ Benzamidine by passing them through a 25G syringe (10-20 strokes) and incubated with agitation for $15 \mathrm{~min}$ at $4^{\circ} \mathrm{C}$ (to ensure complete cell lysis) followed by a centrifugation step at $16,000 \mathrm{rpm}$ for $10 \mathrm{~min}$. The supernatants were either incubated with GST and GSTfusion proteins, respectively, or with GFP-trap beads (ChromoTek, Martinsried, Germany). After incubation for $3 \mathrm{~h}$ GST beads were washed three times with wash buffer $(50 \mathrm{mM}$ Tris/ $\mathrm{HCl}$, pH 7.4, $150 \mathrm{mM} \mathrm{NaCl}$, protease inhibitor cocktail, $0.5 \mathrm{mM}$ PMSF, $0.5 \mathrm{mM}$ EDTA, $1 \mathrm{mM}$ Benzamidine), GFP-trap beads were washed with a different wash buffer $(10 \mathrm{mM}$ Tris/HCl, $\mathrm{pH}$ 7.4, $150 \mathrm{mM}$ $\mathrm{NaCl}$, protease inhibitor cocktail, $0.5 \mathrm{mM}$ PMSF, $0.5 \mathrm{mM}$ EDTA, $1 \mathrm{mM}$ Benzamidine). The beads were resuspended in SDS sample buffer, incubated at $95^{\circ} \mathrm{C}$ for $5 \mathrm{~min}$ and the proteins separated by SDS-PAGE and analyzed by western blot. The $G \beta$ and $G \gamma$ subunits used in this study were previously cloned into GFP (N-terminal) and YFP (Cterminal) vectors, respectively $[85,13]$.

\section{In vitro cross-link assay}

Purified DdRACK1 was used for a multimerization experiment as previously described [86]. Briefly, 5-10 $\mu \mathrm{g} /$ $100 \mu \mathrm{l}$ of RACK1 in $1 \times$ PBS, pH 7.4, was incubated at room temperature in the presence of $0.001 \%(\mathrm{v} / \mathrm{v})$ glutaraldehyde for various time points. The reaction was stopped by addition of glycine to a final concentration of $0.1 \mathrm{M}$ after 5, 10 and $20 \mathrm{~min}$, respectively. Samples were analyzed by SDS-PAGE and western blot.

\section{Test for presence of phosphotyrosine in DdRACK1}

Samples from immunoprecipitation experiments from GFP-DdRACK1 bound to GFP-trap beads in the presence or absence of phosphatase inhibitors were analyzed by western blots and probed with anti-phosphotyrosine monoclonal antibody (5E7) [55].

\section{Immunofluorescence analysis and life cell imaging}

Immunofluorescence study was performed as previously described [82]. Briefly, cells were transferred onto coverslips in Petri dishes and fixed by ice-cold methanol $\left(5 \mathrm{~min}, 20^{\circ} \mathrm{C}\right.$ ). Cells were treated twice for $15 \mathrm{~min}$ (room temperature) with blocking solution $(1 \times$ PBS containing $0.5 \%$ (wt $/ \mathrm{vol}$ ) BSA and $0.1 \%$ (vol/vol) fish gelatin). The appropriate antibodies were diluted in the blocking solution and applied on the cells for $1 \mathrm{~h}$ at room temperature; the excess of antibodies was removed by washing with the blocking solution before the $1 \mathrm{~h}$ 
incubation with the corresponding secondary antibodies. For live cell studies, cells were placed in $35 \mathrm{~mm}$ Petri dishes (ibidi GmbH-Martinsried, Germany) and allowed to adhere to the surface. Analysis of fixed and live cells was done by laser scanning confocal microscopy using a Leica TCS SP5 microscope equipped with a HyD detector.

\section{Cell migration studies}

This analysis was done as previously described $[73,82]$. Briefly, growing cells were plated in a chamber (ibidi GmbH-Martinsried, Germany) and random motility was followed. Images were recorded at intervals of $6 \mathrm{~s}$ using a Leica DM-IL inverse microscope (Deerfield, IL; 40x objective) and a conventional CCD video camera and analyzed using Dynamic Image Analysis Software (DIAS, Soll Technologies, Iowa City, IA).

\section{Miscellaneous methods}

Cell fractionation of AX2 cells was done as previously described [73]. Antibodies used in this study were mouse monoclonal antibodies mAb 47-16-8 directed against $\alpha-$ actinin [87], mAb 33-294 against the cell adhesion molecule csA [88], mAb 188-19-95 against the $32 \mathrm{kDa}$ subunit of heterodimeric capping protein cap32/34 [89], mAb 5E7 against phosphorylated tyrosine residues [55], mAb K3184-2 against GFP [90], mAb act1-7 against actin [91], mAb K73-875-7 against mRFPmars, rabbit polyclonal antibodies against GST [86]. Detection in western blots was with anti-mouse-IgG conjugated to peroxidase or peroxidase conjugated anti-rabbit-IgG antibodies.

For generation of rabbit polyclonal antibodies against DdRACK1, the GST-part of GST-DdRACK1 was removed by thrombin cleavage and DdRACK1 was used to immunize rabbits (Pineda, Berlin, Germany). The antibodies specifically recognized the bacterially produced recombinant protein, the RFP- and GFP-tagged fusion proteins as well as the endogenous protein in western blots of whole cell lysates; they were used in immunoprecipitation experiments as well as for immunofluorescence studies. Monoclonal antibody K73-875-7 was generated against bacterially expressed mRFPmars [83].

Protein sequences of RACK1 proteins from $H$. sapiens (P63244), D. melanogaster (O18640), A. thaliana (O24456), S. cerevisiae (P38011), and D. discoideum (P46800) were retrieved from Uniprot protein database and aligned using ClustalW program with Blosum 62 matrix. The aligned sequences were processed through EsPript for representation. The structural coordinates of $S$. cerevisiae RACK1 (Asc1p) was obtained from protein databank (PBD: 3FRX) (Figure 1B) and used as a template for modelling D. discoideum RACK1. MODELLER v9 was used to generate DdRACK1 model. Structures in Figure $1 \mathrm{~B}$ and $\mathrm{C}$ were generated with the aid of the molecular visualization software PyMOL.

Experiments on animals followed internationally recognized guidelines and were approved by the authorities of the state of Northrhine-Westfalia.

\section{Additional file}

Additional file 1: Figure S1. Distribution of endogenous DdRACK1 in AX2/GFP-G $\beta$ cells. Some enrichment of RACK1 was seen at the cell periphery. Polyclonal RACK1 specific antibodies were used. Nuclei were stained with DAPI. Scale bar, 5 mm. Figure S2. Localization of DdRACK1 in aggregation competent AX2 cells. Aggregation competent AX2 cells formed extensions which are enriched for RACK1 (arrow). RACK1 was detected with polyclonal antibodies, actin with mAb act1-7. Nuclei were stained with DAPI. Scale bar, $5 \mu \mathrm{m}$. Figure S3. Localization of DdRACK1 in polarized cells. In this image, DdRACK1 was seen at the leading edge of polarized aggregation competent cells (arrow). Antibodies were as in Figure S2. Scale bar, 5 Mm. Figure S4. Yeast two-hybrid analyses and $\beta$-galactosidase activity staining. Yeast $Y 190$ strain that has lacZ and His3 reporter genes was co-transformed with DdRACK1 in pACT2 vector and the Ga5, Ga6, Ga7, Ga9 and Ga12 protein subunits in pAS2 vector, respectively. Colonies did not grow on selection plates. Figure S5. Growth on lawns of $K$. aerogenes of AX2/GFP strain. Images of AX2/GFP strain on $K$. aerogenes lawns were taken between days 4 and 6 . Plaque expansion was similar to that of AX2. Scale bar, $1 \mathrm{~mm}$. Figure $\mathbf{S 6}$. Development of AX2/GFP strain on petri dishes under phosphate buffer. $1 \times 10^{7}$ cells were starved on petri dishes and images taken at the indicated time points. The developmental behavior was similar to that of AX2. Scale bar, $250 \mu \mathrm{m}$.

\section{Competing interests}

The authors declare that they have no competing interests.

\section{Authors' contributions}

NNO, KS and TYR planned and performed experiments. MP provided essential contributions to lipid binding and helped with the analysis, AMT provided essential reagents for antibody generation. AAN and TYR designed and supervised the study. NNO, AAN and TYR wrote the manuscript. All authors read and approved the final manuscript.

\section{Acknowledgements}

This work was supported by the DFG and SFB670. TYR acknowledges support from the Professorinnen Program of the University of Cologne. We thank Dr. V. Peche for helpful comments, Drs. S. Bozzaro, G. Gerisch and B. Peracino for providing strains and reagents, dictyBase for strains, and B. Gaßen for antibody generation.

\section{Author details}

${ }^{1}$ Institute of Biochemistry I, Medical Faculty, Center for Molecular Medicine Cologne (CMMC) and Cologne Excellence Cluster on Cellular Stress Responses in Aging-Associated Diseases (CECAD), University of Cologne, 50931 Köln, Germany. ${ }^{2}$ Institute of Biochemistry II, Medical Faculty, University of Cologne, 50931 Köln, Germany. Institute of Anatomy and Cell Biology, Ludwig-Maximilians-University, 80336 München, Germany.

Received: 21 February 2014 Accepted: 6 June 2014 Published: 15 June 2014

\section{References}

1. Gilman AG: G proteins: transducers of receptor-generated signals. Annu Rev Biochem 1987, 56:615-649.

2. Sprang SR: $G$ protein mechanisms: insights from structural analysis. Annu Rev Biochem 1997, 66:639-678.

3. Hamm HE: The many faces of G protein signaling. J Biol Chem 1998 , 273:669-672.

4. Clapham DE, Neer EJ: G protein $\beta y$ subunits. Annu Rev Pharmacol Toxicol 1997, 37:167-203. 
5. Sondek J, Siderovski DP: Ggamma-like (GGL) domains: new frontiers in G-protein signaling and $\beta$-propeller scaffolding. Biochem Pharmacol 2001, 61:1329-1337

6. Schulz R: The pharmacology of phosducin. Pharmacol Res 2001, 43:1-10.

7. Inglese J, Luttrell LM, Iñiguez-Lluhi JA, Touhara K, Koch WJ, Lefkowitz RJ: Functionally active targeting domain of the $\beta$ - adrenergic receptor kinase: an inhibitor of $\mathrm{G} \beta \gamma$-mediated stimulation of type II adenylyl cyclase. Proc Natl Acad Sci 1994, 91:3637-3641

8. Neer EJ, Schmidt CJ, Nambudripad R, Smith TF: The ancient regulatoryprotein family of WD-repeat proteins. Nature 1994, 371:297-300.

9. Neer EJ, Smith TF: G protein heterodimers: new structures propel new questions. Cell 1996, 84:175-178.

10. Whiteway M, Hougan L, Dignard D, Thomas DY, Bell L, Saari GC, Grant FJ, O'Hara P, Mackay VL: The STE4 and STE18 genes of yeast encode potential beta and gamma subunits of the mating factor receptorcoupled G protein. Cell 1989, 56:467-477.

11. Brzostowski JA, Kimmel AR: Signaling at zero G: G protein-independent functions for 7-TM receptors. Trends Biochem Sci 2001, 26:291-297.

12. Wu L, Valkema R, Van Haastert PJM, Devreotes PN: The G protein b subunit is essential for multiple responses to chemoattractants in Dictyostelium. J Cell Biol 1995, 129:1667-1675.

13. Zhang N, Long Y, Devreotes PN: Ggamma in Dictyostelium: its role in localization of gbetagamma to the membrane is required for chemotaxis in shallow gradients. Mol Biol Cell 2001, 12:3204-3213.

14. Okaichi K, Cubitt AB, Pitt GS, Firtel RA: Amino acid substitutions in the Dictyostelium Ga subunit Ga2 produce dominant negative phenotypes and inhibit the activation of adenylyl cyclase, guanylyl cyclase and phospholipase C. Mol Biol Cell 1992, 3:735-747.

15. Srinivasan J, Gundersen RE, Hadwiger JA: Activated Galpha Subunits Can Inhibit Multiple Signal Transduction Pathways during Dictyostelium Development. Dev Biol 1999, 215:443-452.

16. $\mathrm{Wu} Y$, Janetopoulos $\mathrm{C}$ : The $\mathrm{G}$ alpha subunit 8 inhibits proliferation, promotes adhesion and regulates cell differentiation. Dev Biol 2013, 380:58-72.

17. Wu L, Gaskins C, Zhou K, Firtel RA, Devreotes PN: Cloning and targeted mutations of $\mathrm{G}$ alpha 7 and $\mathrm{G}$ alpha 8, two developmentally regulated $\mathrm{G}$ protein alpha-subunit genes in Dictyostelium. Mol Biol Cell 1994, 5:691-702.

18. Peracino B, Borleis J, Jin T, Westphal M, Schwartz JM, Wu L, Bracco E, Gerisch G, Devreotes P, Bozzaro S: G protein beta subunit-null mutants are impaired in phagocytosis and chemotaxis due to inappropriate regulation of the actin cytoskeleton. J Cell Biol 1998, 29:1529-1537.

19. Brandon MA, Voglmaier S, Siddiqi AA: Molecular characterization of a Dictyostelium G-protein alpha-subunit required for development. Gene 1997, 200:99-105.

20. Hadwiger JA, Lee S, Firtel RA: The $G$ alpha subunit $G$ alpha 4 couples to pterin receptors and identifies a signaling pathway that is essential for multicellular development in Dictyostelium. Proc Natl Acad Sci 1994, 91:10566-10570.

21. Kumagai A, Pupillo M, Gundersen R, Maike LR, Devreotes PN, Firtel RA: Regulation and function of $\mathrm{G}$ alpha protein subunits in Dictyostelium. Cell 1989, 57:265-275.

22. Volta V, Beugnet A, Gallo S, Magri L, Brina D, Pesce E, Calamita P, Sanvito F, Biffo S: RACK1 depletion in a mouse model causes lethality, pigmentation deficits and reduction in protein synthesis efficiency. Cell Mol Life Sci 2013, 70:1439-1450.

23. Ron D, Chen CH, Caldwell J, Jamieson L, Orr E, Mochly-Rosen D: Cloning of an intracellular receptor for protein kinase C: a homolog of the beta subunit of G proteins. Proc Natl Acad Sci 1994, 91:839-843.

24. Ron D, Jiang Z, Yao L, Vagts A, Diamond I, Gordon A: Coordinated movement of RACK1 with activated betallPKC. J Biol Chem 1999, 274:27039-27046.

25. Neasta J, Kiely PA, He DY, Adams DR, O'Connor R, Ron D: Direct interaction between scaffolding proteins RACK1 and 14-3-3zeta regulates brain derived neurotrophic factor (BDNF) transcription. J Biol Chem 2012, 287:322-336.

26. Dell EJ, Connor J, Chen S, Stebbins EG, Skiba NP, Mochly-Rosen D, Hamm HE: The beta gamma subunit of heterotrimeric $G$ proteins interacts with RACK1 and two other WD repeat proteins. J Biol Chem 2002, 277:49888-49895.

27. Chen S, Dell EJ, Lin F, Sai J, Hamm HE: RACK1 regulates specific functions of Gbetagamma. J Biol Chem 2004, 279:17861-17868.
28. Chen S, Lin F, Hamm HE: RACK1 binds to a signal transfer region of G betagamma and inhibits phospholipase $C$ beta2 activation. J Biol Chem 2005, 280:33445-33452.

29. Palmer AD, Thomson JK, Li L, Prat A, Wang P: Gib2, a novel G $\beta$-like/Rack1 homolog, functions as a G $\beta$ subunit in CAMP signaling and is essential in Cryptococcus neoformans. J Biol Chem 2006, 281:32596-32605.

30. Zeller CE, Parnell SC, Dohlman HG: The Rack1 Ortholog Asc1 Functions as a $\mathrm{G}$ protein $\beta$ Subunit Coupled to Glucose Responsiveness in Yeast. J Biol Chem 2007, 282:25168-25176.

31. Adams DR, Ron D, Kiely PA: RACK1: a multifaceted scaffolding protein: structure and function. Cell Commun Signal 2011, 9:22.

32. Gandin V, Senft D, Topisirovic I, Ronai ZA: RACK1 function in cell motility and protein synthesis. Gene and Cancer 2013, 4:369-377.

33. Riyahi TY, Frese F, Steinert M, Omosigho NN, Glöckner G, Eichinger L, Orabi B, Williams RS, Noegel AA: RpkA, a highly conserved GPCR with a lipid kinase domain, has a role in phagocytosis and anti-bacterial defense. PLoS One 2011, 6:e27311.

34. Wall MA, Coleman DE, Lee E, Iniguez-Lluhi JA, Posner BA, Gilman AG, Sprang SR: The structure of the $\mathrm{G}$ protein heterotrimer $\mathrm{Gi}$ alpha 1 beta 1 gamma 2. Cell 1995, 83:1047-1058

35. Sondek J, Bohm A, Lambright DG, Hamm HE, Sigler PB: Crystal structure of a G-protein beta gamma dimer at $2.1 \AA$ resolution. Nature 1996, 379:369-374.

36. Lambright DG, Sondek J, Bohm A, Skiba NP, Hamm HE, Sigler PB: The $2.0 \AA$ crystal structure of a heterotrimeric G protein. Nature 1996, 379:311-319.

37. Coyle SM, Gilbert WV, Doudna JA: Direct link between RACK1 function and localization at the ribosome in vivo. Mol Cell Biol 2009, 29:1626-1634.

38. Rabl J, Leibundgut M, Ataide SF, Haag A, Ban N: Crystal structure of the eukaryotic 40S ribosomal subunit in complex with initiation factor 1. Science 2011, 331:730-736

39. Coyle H, Scappini EL, Moon AF, Williams LV, Armstrong DL, Pedersen LC: Structure of a signal transduction regulator, RACK1, from Arabidopsis thaliana. Protein Sci 2008, 17:1771-1780.

40. Yatime L, Hein KL, Nilsson J, Nissen P: Structure of the RACK1 dimer from Saccharomyces cerevisiae. J Mol Biol 2011, 411:486-498.

41. Ruiz CD, Chandrasekaran R, Nilsson M, Cornvik T, Liew CW, Tan SM, Lescar J: Structure of human RACK1 protein at a resolution of $2.45 \AA$. Acta Cryst 2012, 68:867-872.

42. Boulais J, Trost M, Landry CR, Dieckmann R, Levy ED, Soldati T, Michnick SW, Thibault P, Desjardins M: Molecular characterization of the evolution of phagosomes. Mol Syst Biol 2010, 6:423.

43. Gotthardt D, Blancheteau V, Bosserhoff A, Ruppert T, Delorenzi M, Soldati T: Proteomics fingerprinting of phagosome maturation and evidence for the role of a Ga during uptake. Mol Cell Proteomics 2006, 5:2228-2243.

44. Rogers LD, Foster LJ: The dynamic phagosomal proteome and the contribution of the endoplasmic reticulum. Proc Natl Acad Sci 2007, 104:18520-18525.

45. Urwyler S, Nyfeler Y, Ragaz C, Lee H, Mueller LN, Aebersold R, Hilbe H: Proteome analysis of Legionella vacuoles purified by magnetic immunoseparation reveals secretory and endosomal GTPases. Traffic 2009, 10:76-87.

46. Thornton C, Tang KC, Phamluong K, Luong K, Vagts A, Nikanjam D, Yaka R, Ron D: Spatial and temporal regulation of RACK1 function and N-methylD-aspartate receptor activity through WD40 motif mediated dimerization. J Biol Chem 2004, 279:31357-31364.

47. Liu YV, Hubbi ME, Pan F, McDonald KR, Mansharamani M, Cole RN, Liu JO, Semenza GL: Calcineurin promotes hypoxia-inducible factor 1alpha expression by dephosphorylating RACK1 and blocking RACK1 dimerization. J Biol Chem 2007, 282:37064-37073.

48. Sengupta J, Nilsson J, Gursky R, Spahn CM, Nissen P, Frank J: Identification of the versatile scaffold protein RACK1 on the eukaryotic ribosome by cryo EM. Nat Struct Mol Biol 2004, 11:957-962.

49. Kiely PA, O'Gorman D, Luong K, Ron D, O'Connor R: Insulin-like growth factor I controls a mutually exclusive association of RACK1 with protein phosphatase $2 \mathrm{~A}$ and beta1 integrin to promote cell migration. $\mathrm{Mol} \mathrm{Cell} \mathrm{Biol}$ 2006, 26:4041-4051.

50. Kiely PA, Baillie GS, Lynch MJ, Houslay MD, O'Connor R: Tyrosine 302 in RACK1 is essential for insulin-like growth factor-l-mediated competitive binding of PP2A and beta1 integrin and for tumor cell proliferation and migration. J Biol Chem 2008, 283:22952-22961.

51. Kiely PA, Baillie GS, Barrett R, Buckley DA, Adams DR, Houslay MD, O'Connor $R$ : Phosphorylation of RACK1 on tyrosine 52 by c-Abl is required for 
insulin-like growth factor I-mediated regulation of focal adhesion kinase. J Biol Chem 2009, 284:20263-20274.

52. Chang BY, Chiang M, Cartwright CA: The interaction of Src and RACK1 is enhanced by activation of protein kinase $C$ and tyrosine phosphorylation of RACK1.J Biol Chem 2001, 276:20346-20356.

53. Mamidipudi V, Dhillon NK, Parman T, Miller LD, Lee KC, Cartwright CA RACK1 inhibits colonic cell growth by regulating Src activity at cell cycle checkpoints. Oncogene 2007, 26:2914-2924.

54. Mamidipudi V, Miller LD, Mochly-Rosen D, Cartwright CA: Peptide modulators of Src activity in G1 regulate entry into S phase and proliferation of $\mathrm{NIH}$ 3 T3 cells. Biochem Biophys Res Commun 2007, 352:423-430.

55. Fendly BM, Winget M, Hudziak RM, Lipari MT, Napier MA, Ullrich A: Characterization of murine monoclonal antibodies reactive to either the human epidermal growth factor receptor or HER2/neu gene product. Cancer Res 1990, 1:1550-1558.

56. DeFord-Watts LM, Dougall DS, Belkaya S, Johnson BA, Eitson JL, Roybal KT, Barylko B, Albanesi JP, Wülfing C, van Oers NSC: The CD3 z subunit contains a phosphoinositide-binding motif that is required for the table accumulation of TCR-CD3 complex at the immunological synapse. J Immun 2011, 186:6839-6847.

57. Narayan K, Lemmon MA: Determining selectivity of phosphoinositidebinding domains. Methods 2006, 39:122-133.

58. Hermanto U, Zong CS, Li WW, Wang LH: RACK1, an insulin-like growth factor I (IGF-I) receptor-interacting protein, modulates IGF-I-dependent integrin signaling and promotes cell spreading and contact with extracellular matrix. Mol Cell Biol 2002, 22:2345-2365.

59. Mamidipudi V, Zhang J, Lee KC, Cartwright CA: RACK1 regulates G1/S progression by suppressing Src kinase activity. Mol Cell Biol 2004, 24:6788-6798.

60. Chen S, Lin F, Shin ME, Wang F, Shen L, Hamm HE: RACK1 regulates directional cell migration by acting on $\mathrm{G}$ betagamma at the interface with its effectors PLC beta and PI3K gamma. Mol Biol Cell 2008, 19:3909-3922.

61. Liu W, Dou F, Feng J, Yan Z: RACK1 is involved in beta-amyloid impairment of muscarinic regulation of GABAergic transmission. Neurobiol Aging 2011, 32:1818-1826.

62. Ron D, Adams DR, Baillie GS, Long A, O'Connor R, Kiely PA: RACK (1) to the future- a historical perspective. Cell Commun Signal 2013, 11:53.

63. Ron D, Mochly-Rosen D: An autoregulatory region in protein kinase C: the pseudoanchoring site. Proc Natl Acad Sci 1995, 92:492-496.

64. Garcia-Higuera I, Fenoglio J, Li Y, Lewis C, Panchenko MP, Reiner O, Smith TF, Neer EJ: Folding of proteins with WD-repeats: comparison of six members of the WD-repeat superfamily to the $G$ protein $b$ subunit. Biochem 1996, 35:13985-13994

65. Sklan EH, Podoly E, Soreq H: RACK1 has the nerve to act: structure meets function in the nervous system. Prog Neurobiol 2006, 78:117-134.

66. McCahill A, Warwicker J, Bolger GB, Houslay MD, Yarwood SJ: The RACK1 scaffold protein: a dynamic cog in cell response mechanisms. Mol Pharmacol 2002, 62:1261-1273.

67. Cox EA, Bennin D, Doan AT, O'Toole T, Huttenlocher A: RACK1 regulates integrin-mediated adhesion, protrusion, and chemotactic cell migration via its Src-binding site. Mol Biol Cell 2003, 14:658-669.

68. Onishi I, Lin PJ, Diering GH, Williams WP, Numata M: RACK1 associates with NHE5 in focal adhesions and positively regulates the transporter activity. Cell Signal 2007, 19:194-203.

69. Buensuceso CS, Woodside D, Huff JL, Plopper GE, OToole TE: The WD protein Rack1 mediates protein kinase $\mathrm{C}$ and integrin-dependent cell migration. J Cell Sci 2001, 114:1691-1698.

70. Buensuceso CS, Obergfell A, Soriani A, Eto K, Kiosses WB, Arias-Salgado EG, Kawakami T, Shattil SJ: Regulation of outside-in signaling in platelets by integrin-associated protein kinase C beta. J Biol Chem 2005, 280:644-653.

71. Chang BY, Harte RA, Cartwright CA: RACK1: a novel substrate for the SrC protein-tyrosine kinase. Oncogene 2002, 21:7619-7629.

72. Kutateladze TG: Translation of the phosphoinositide code by PI effectors. Nat Chem Biol 2010, 6:507-513.

73. Müller R, Herr C, Sukumaran SK, Omosigho NN, Plomann M, Riyahi TY, Stumpf M, Swaminathan K, Tsangarides M, Yiannakou K, Blau-Wasser R, Gallinger C, Schleicher M, Kolanus W, Noegel AA: The cytohesin paralog Sec7 of Dictyostelium discoideum is required for phagocytosis and cell motility. Cell Commun Signal 2013, 11:54.

74. Kölsch V, Charest PG, Firtel RA: The regulation of cell motility and chemotaxis by phospholipid signaling. J Cell Sci 2008, 121:551-559.
75. Hoeller O, Kay RR: Chemotaxis in the absence of PIP3 gradients. Curr Biol 2007, 17:813-817.

76. Devreotes PN: G protein-linked signaling pathways control the developmental program of Dictyostelium. Neurone 1994, 12:235-241.

77. Firtel RA: Signal transduction pathways controlling multicellular development in Dictyostelium. Trends Genet 1991, 7:381-388.

78. Wu L, Gaskins C, Gundersen R, Hadwiger J, Johnson R, Pitt G, Firtel R, Devreotes PN: Signal Transduction by G proteins in Dictyostleium discoideum. In GTPasees in Biology II. 108th edition. Edited by Dickey B, Birnbaumer L. ; 1993:335-349.

79. Firtel RA: Interacting signaling pathways controlling multicellular development in Dictyostelium. Curr Opin Genet Devel 1996, 6:545-554

80. Harloff C, Gerisch G, Noegel AA: Selective elimination of the contact site A protein of Dictyostelium discoideum by gene disruption. Genes Dev 1989, 3:2011-2019.

81. Noegel A, Harloff C, Hirth P, Merkl R, Modersitzki M, Stadler J, Weinhart U, Westphal M, Gerisch G: Probing an adhesion mutant of Dictyostelium discoideum with CDNA clones and monoclonal antibodies indicates a specific defect in the contact site A glycoprotein. EMBO J 1985, 4:3805-3810.

82. Blau-Wasser R, Euteneuer U, Xiong H, Gassen B, Schleicher M, Noegel AA: CP250, a novel acidic coiled-coil protein of the Dictyostelium centrosome, affects growth, chemotaxis, and the nuclear envelope. Mol Biol Cell 2009, 20:4348-4361.

83. Fischer M, Haase I, Simmeth E, Gerisch G, Müller-Taubenberger A: A brilliant monomeric red fluorescent protein to visualize cytoskeleton dynamics in Dictyostelium. FEBS Lett 2004, 5:227-232.

84. Blume JJ, Halbach A, Behrendt D, Paulsson M, Plomann M: EHD proteins are associated with tubular and vesicular compartments and interact with specific phospholipids. Exp Cell Res 2007, 313:219-231.

85. Jin $T$, Zhang $N$, Long $Y$, Parent CA, Devreotes PN: Localization of the $G$ protein betagamma complex in living cells during chemotaxis. Science 2000, 287:1034-1036.

86. Xiong H, Rivero F, Euteneuer U, Mondal S, Mana-Capelli S, Larochelle D, Vogel A, Gassen B, Noegel AA: Dictyostelium Sun-1 connects the centrosome to chromatin and ensures genome stability. Traffic 2008, 9:708-724.

87. Schleicher M, Gerisch G, Isenberg G: New actin-binding proteins from Dictyostelium discoideum. EMBO J 1984, 3:2095-2100.

88. Berthold J, Stadler J, Bozzaro S, Fichtner B, Gerisch G: Carbohydrate and other epitopes of the contact site A glycoprotein of Dictyostelium discoideum as characterized by monoclonal antibodies. Cell Differ 1985, 16:187-202

89. Haus U, Trommler P, Fisher PR, Hartmann H, Lottspeich F, Noegel AA, Schleicher M: The heat shock cognate protein from Dictyostelium affects actin polymerization through interaction with the actin-binding protein cap32/34. EMBO J 1993, 12:3763-3771.

90. Noegel AA, Blau-Wasser R, Sultana H, Müller R, Israel L, Schleicher M, Patel H, Weijer CJ: The cyclase-associated protein CAP as regulator of cell polarity and cAMP signaling in Dictyostelium. Mol Biol Cell 2004, 15:934-945.

91. Simpson PA, Spudich JA, Parham P: Monoclonal antibodies prepared against Dictyostelium Actin: characterization and interactions with Actin. J Cell Biol 1984, 99:287-295.

doi:10.1186/1478-811X-12-37

Cite this article as: Omosigho et al:: The Dictyostelium discoideum RACK1 orthologue has roles in growth and development. Cell Communication and Signaling 2014 12:37. 